\title{
Remote Forcing of Tasman Sea Marine Heatwaves
}

\author{
ZEYA Li AND NEIL J. HOLBROOK \\ Institute for Marine and Antarctic Studies, and Australian Research Council Centre of Excellence for Climate Extremes, \\ University of Tasmania, Hobart, Tasmania, Australia \\ XUEBIN ZHANG \\ Centre for Southern Hemisphere Oceans Research, CSIRO Oceans and Atmosphere, Hobart, Tasmania, Australia \\ ERIC C. J. OLIVER \\ Australian Research Council Centre of Excellence for Climate Extremes, and Department of Oceanography, Dalhousie \\ University, Halifax, Nova Scotia, Canada

\section{Eva A. Cougnon} \\ Institute for Marine and Antarctic Studies, University of Tasmania, Hobart, Tasmania, Australia
}

(Manuscript received 21 August 2019, in final form 19 March 2020)

\begin{abstract}
Recent marine heatwave (MHW) events in the Tasman Sea have had dramatic impacts on the ecosystems, fisheries, and aquaculture off Tasmania's east coast. However, our understanding of the large-scale drivers (forcing) and potential predictability of MHW events in this region off southeast Australia is still in its infancy. Here, we investigate the role of oceanic Rossby waves forced in the interior South Pacific on observed MHW occurrences off southeast Australia from 1994 to 2016, including the extreme 2015/16 MHW event. First, we used an upper-ocean heat budget analysis to show that 51\% of these historical Tasman Sea MHWs were primarily due to increased East Australian Current (EAC) Extension poleward transports through the region. Second, we used lagged correlation analysis to empirically connect the EAC Extension intensification to incoming westward-propagating sea surface height (SSH) anomalies from the interior South Pacific. Third, we dynamically analyzed these SSH anomalies using simple process-based baroclinic and barotropic Rossby wave models forced by wind stress curl changes across the South Pacific. Finally, we show that associated monthly SSH changes around New Zealand may be a useful index of western Tasman Sea MHW predictability, with a lead time of 2-3 years. In conclusion, our findings demonstrate that there is potential predictability of advection-dominated MHW event likelihoods in the EAC Extension region up to several years in advance, due to the deterministic contribution from baroclinic and barotropic Rossby waves in modulating the EAC Extension transports.
\end{abstract}

\section{Introduction}

Marine heatwaves (MHWs) can have profound impacts on marine ecosystems (e.g., Hughes et al. 2018; Babcock et al. 2019; Smale et al. 2019). Recent estimates indicate that the frequency, intensity, and duration of MHWs have been increasing globally (Oliver et al. 2018), which is consistent with simple long-term warming (Oliver 2019). Nevertheless, it is these discrete prolonged extreme events known as MHWs that are more

Corresponding author: Zeya Li, zeya.li@utas.edu.au impactful on ecosystems than the background slow warming trend (Smale et al. 2019). Further, warm-water species, introduced as a result of MHWs, can also perturb ecosystems in some regions, damaging system structures and influencing system functions (Cavole et al. 2016).

The 2015/16 Tasman Sea MHW was the longest and most intense ocean warming event ever recorded off southeast Australia (Oliver et al. 2017). This extreme warming event lasted from September 2015 to May 2016 , with a maximum intensity of $\sim 3^{\circ} \mathrm{C}$ analyzed within the southeast Australia (SEAus) region bounded by 


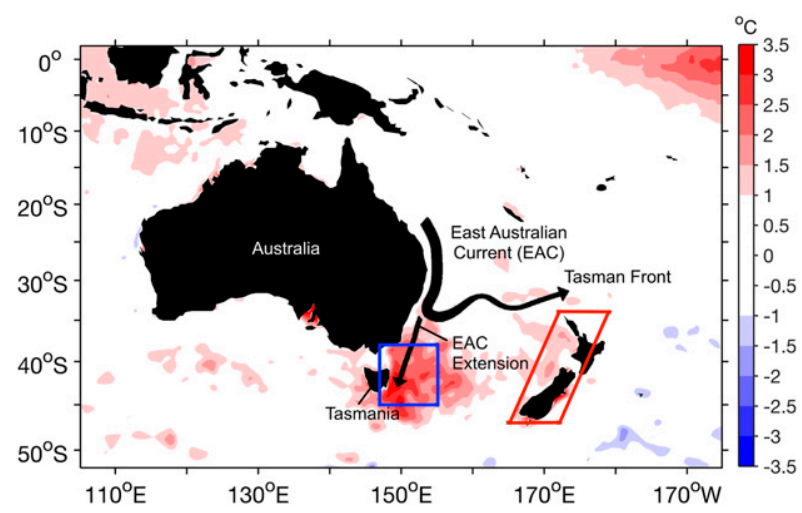

FIG. 1. The mean sea surface temperature (SST) anomalies for the 2015/16 austral summer (December-February) relative to the 1982-2011 climatology from NOAA OI SST. The blue rectangle highlights the SEAus region. The red trapezoid defines the region around New Zealand analyzed in this study as a recipient and source of SSH anomalies from Rossby waves.

$45^{\circ}-37^{\circ} \mathrm{S}, 147^{\circ}-155^{\circ} \mathrm{E}$ (Oliver et al. 2017) (Fig. 1, blue box). Corresponding to this event, there were substantial impacts including reduced performance of farmed Atlantic salmon and mortality of blacklip abalone (Gramenz 2016; Oliver et al. 2017).

Understanding the mechanisms that cause MHWs may be beneficial to their potential predictability (Holbrook et al. 2019), and hence to marine ecosystem management response strategies and planning. These mechanisms can be broken down into local processes and large-scale climate mode drivers and teleconnections (Holbrook et al. 2019). Based on an upper-ocean temperature budget analysis, Oliver et al. (2017) determined that the dominant local physical process causing the 2015/16 Tasman Sea MHW was horizontal ocean advection, due to the anomalously strong East Australian Current (EAC) Extension at the time. However, the large-scale driver of the intensified EAC Extension during this period was not investigated.

From a large-scale perspective, the strength of the EAC Extension is connected to variations in the South Pacific wind forcing (e.g., Ganachaud et al. 2014). Dynamically, wind forcing plays a fundamental role in the strength and character of the ocean subtropical gyre (Sverdrup 1947; Stommel 1948). Specifically, within the gyre, variations of western boundary current transports are a response to changes in the interior winds (e.g., Hill et al. 2010; Andres et al. 2011; Zhang et al. 2012). This relationship between the western boundary current intensity and the interior wind forcing is mainly adjusted by wind-forced Rossby waves (Anderson and Gill 1975; Chelton and Schlax 1996). For the North Pacific Subtropical Gyre, previous studies identified that Rossby waves generated due to changes in wind stress

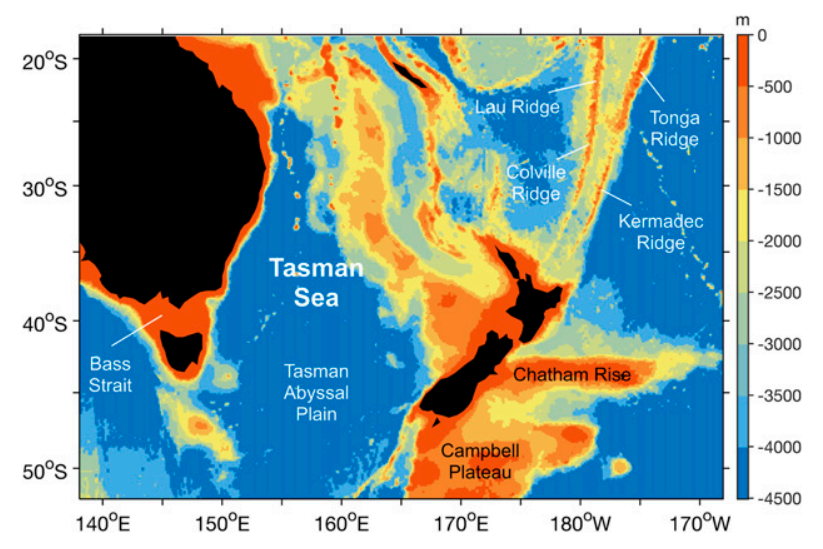

FIG. 2. Bathymetry of the southwest Pacific with notable bathymetric features labeled. Colors indicate the bathymetric depths across the region derived from BRAN2016.

curl propagate from the interior North Pacific into the Kuroshio Extension region, and modulate the strength of Kuroshio Extension (e.g., Deser et al. 1999; Qiu et al. 2007; Ceballos et al. 2009). For the South Pacific Subtropical Gyre, the western boundary current system consists of the EAC and its extension (Fig. 1). Variations in the EAC and its extension can be identified as a response to changes in the South Pacific wind field, where oceanic Rossby waves are the important teleconnections (e.g., Hill et al. 2010; Holbrook et al. 2011).

Aside from the critical role of the wind field, the presence of land (and topography) also plays an important role in explaining the western boundary current transport and separation of the EAC (e.g., Bull et al. 2018). Liu et al. (1999) explain that wind-forced westward-propagating Rossby waves from the interior South Pacific reach the east coast of New Zealand and initiate a coastal Kelvin wave that rapidly propagates anticlockwise around the island; then, the coastal Kelvin wave spawns new Rossby waves on the west coast of New Zealand; finally, these new Rossby waves propagate toward Australia. In terms of bathymetry, and according to Fig. 2, on the northeast side of New Zealand, a doubleridge system blocks off the eastern entrance of the Tasman Sea. Based on a North Pacific example, Tanaka and Ikeda (2004) show that barotropic Rossby waves appear to convert to baroclinic modes while propagating across ridges. They point out that this interaction between barotropic and baroclinic Rossby waves could result in a stalling of wave propagation at ridges.

The aims of this study were 1) to identify the largescale forcing mechanisms of the 2015/16 Tasman Sea MHW and 2) to identify the dominant local processes and large-scale forcing mechanisms of historical MHWs in the Tasman Sea since 1994. The study focused on three key objectives. First, we identified all historical 
Tasman Sea MHW occurrences from 1994 to 2016, and performed an upper-ocean heat budget analysis to identify those events driven primarily by ocean advection (meridional advection due to changes in EAC Extension intensity) or other factors (e.g., enhanced downward air-sea heat flux). Second, we applied lagged correlation analysis to establish connections between the EAC Extension transports and sea surface height ( $\mathrm{SSH}$ ) anomalies in the South Pacific, suggesting the influence of Rossby waves in modulating the western boundary current intensity. Third, we simulated the SSH anomalies from 1994 to 2016 using wind-forced baroclinic and barotropic Rossby wave models. We compared the model-simulated SSH field with SSH and wind stress curl anomalies from reanalysis data, dynamically confirming the role of Rossby waves and linking them with wind stress curl anomalies in the interior South Pacific. By pulling together the threads of the results in three parts, we have provided a comprehensive analysis of the local processes and large-scale forcing mechanisms that have historically caused Tasman Sea MHWs.

\section{Data and methods}

\section{a. Data}

A high-quality gridded dataset of sea surface temperature (SST) is required for MHW detection (Hobday et al. 2016). The daily NOAA Optimum Interpolation (OI) SST dataset (Reynolds et al. 2007) is a combined product of observations from different platforms including satellite, ships, and buoys. These global SST data are provided on a $0.25^{\circ}$ grid and daily in time from late 1981 to the present. This dataset is of sufficient length, consistency, and continuity (Banzon et al. 2016), and ideally suited to detect MHWs and estimate their characteristics in detail.

For subsurface information, we use the Bluelink Reanalysis (BRAN) 2016 data (Oke et al. 2013), which provide daily records of physical variables (e.g., temperature, sea level, velocity) describing the ocean circulation on a $0.1^{\circ}$ grid since 1994 . BRAN is a multiyear integration of the Ocean Forecasting Australia Model (OFAM), which assimilates available observations using the Bluelink Ocean Data Assimilation System (BODAS). As the latest publicly available version, BRAN2016 includes substantial updates on the previous versions and leads to smaller misfits with observations (Oke et al. 2013). BRAN2016 provides a realistic reconstruction of the mesoscale upper ocean dynamics (especially around Australia) and is suitable for various applications including ocean variability analysis, extreme events, and process studies (Oke et al. 2013).

\section{b. Quantitative marine heatwave definition}

Hobday et al. (2016) qualitatively define a MHW to be a prolonged discrete anomalously warm water event in a particular location. Quantitatively, "prolonged" denotes that the event must persist for 5 or more days, "discrete" indicates that the event can be identified by specific start and end dates, and "anomalously warm" means that water during the event is warmer than an upper-percentile threshold (typically 90th percentile) relative to a long-period baseline climatology (typically 30 years). For this quantitative definition, two successive events disconnected by a gap of 2 days or less are combined and identified as a single continuous event. Using this definition, it is now possible to detect MHWs at any point in the ocean, provided we have daily records of water temperature. The main characteristics of detected MHWs can also be estimated from these data including duration (the number of days between start and end dates), mean and maximum intensity (the mean and maximum temperature anomalies during the MHW), and cumulative intensity (the sum of daily temperature anomalies over the whole period of the MHW).

In this study, MHWs off southeast Australia were detected from daily NOAA OI SST time series, defined by SSTs being five or more days duration in excess of the 90th percentile above a 30-yr baseline climatology over 1982-2011. The area of interest follows Oliver et al. (2017) (i.e., the SEAus region).

\section{c. Upper-ocean heat budget analysis}

To identify MHWs attributable to the EAC Extension intensifications, an upper-ocean heat budget analysis was used to estimate the relative contribution from divergent advection to the near-surface (mixed layer average) heat tendency during these events. The budget can be expressed in the form of a volume-averaged equation (e.g., Benthuysen et al. 2014; Oliver et al. 2017):

$$
\underbrace{\rho c_{p} \frac{d\langle T\rangle}{d t}}_{Q_{t}}=\underbrace{-\rho c_{p}\langle\mathbf{V} \cdot \nabla T\rangle}_{Q_{\text {adv }}}+\underbrace{\frac{1}{A} \int^{A} \frac{Q}{h} d A}_{Q_{\text {surf }}}+\underbrace{\rho c_{p}\left\langle\nabla_{H} \cdot\left(\kappa_{H} \nabla_{H} T\right)\right\rangle-\frac{\rho c_{p}}{A} \int^{A}\left(\kappa_{V} \frac{d T}{d z}\right)_{-h}^{d A}}_{Q_{\text {resi }}}
$$


with $\langle\cdots\rangle=(1 / h A) \int^{A} \int_{-h}^{0} \cdots d z d A$. Here, $\rho c_{p}\left(\mathrm{~J}^{\circ} \mathrm{C}^{-1} \mathrm{~m}^{-3}\right)$ is the volumetric heat capacity of seawater, $T\left({ }^{\circ} \mathrm{C}\right)$ is ocean temperature, $\mathbf{V}$ is the velocity vector with zonal, meridional, and vertical directional elements $u\left(\mathrm{~m} \mathrm{~s}^{-1}\right), v\left(\mathrm{~m} \mathrm{~s}^{-1}\right)$, and $w\left(\mathrm{~m} \mathrm{~s}^{-1}\right), \nabla$ and $\nabla_{H}$ are three-dimensional and horizontal gradient operators, respectively, $\kappa_{H}\left(\mathrm{~m}^{2} \mathrm{~s}^{-1}\right)$ and $\kappa_{V}\left(\mathrm{~m}^{2} \mathrm{~s}^{-1}\right)$ are horizontal and vertical diffusion coefficients, and $Q$ $\left(\mathrm{W} \mathrm{m}^{-2}\right)$ is the net air-sea heat flux. The depth $h(m)$ and area $A\left(\mathrm{~m}^{2}\right)$ are used together to define the averaged volume of the study domain. For the terms of the equation, $Q_{t}$ is the time rate of total change in volume-averaged heating (i.e., heat tendency), $Q_{\text {adv }}$ is the time rate of change in volume-averaged heating due to advection, and $Q_{\text {surf }}$ is the time rate of change owing to air-sea heat flux. The $Q_{\text {resi }}$ term is the time rate of change contributed by other factors including horizontal and vertical diffusion.

We carry out the heat budget analysis following Eq. (1) but calculate the advection term using a modified scheme. To explore the relationship between Tasman Sea MHWs and EAC Extension transport anomalies, we are interested in not only the total advection, but also its meridional component along the direction of EAC Extension. For the traditional advection scheme in Eq. (1), its individual directional elements excessively include processes that control the redistribution of heating within the domain but do not affect the volumeaveraged heating of the domain (Lee et al. 2004). Hence, a modified advection scheme in which all these internal processes are removed is introduced. Referring to previous applications in the eastern equatorial Pacific during several El Niño-Southern Oscillation (ENSO) events (e.g., Lee et al. 2004; Kim et al. 2007; Zhang and McPhaden 2010), this modified scheme is able to provide explicit estimations for individual directional advections.

Following Lee et al. (2004), the modified scheme $Q_{\text {advs }}$ describes the advection across the bounding interface $S$ of the study domain and is expressed as

$$
Q_{\mathrm{adv} S}=-\rho c_{p} \int_{S}\left(\mathbf{V}_{s} \cdot \mathbf{n}\right)\left(T_{S}-\langle T\rangle\right) d S,
$$

where $\mathbf{V}_{s}$ is the velocity vector at $S, \mathbf{n}$ is the normal unit vector pointing outward from $S, T_{S}$ is the temperature at $S$, and $\langle T\rangle$ is the volume-averaged temperature of the domain. By using this modified scheme, we are able to estimate both individual directional and total heat advections into/out of the domain in a clear and straightforward way. For example, $Q_{\text {advMeridional }}$ describes advection in the meridional direction and can be calculated following

$$
\begin{aligned}
Q_{\text {advMeridional }}= & Q_{\text {advSouth }}+Q_{\text {advNorth }} \\
= & \rho c_{p} \int_{S_{\text {South }}} v\left(T_{\text {South }}-\langle T\rangle\right) d S_{\text {South }} \\
& -\rho c_{p} \int_{S_{\text {North }}} v\left(T_{\text {North }}-\langle T\rangle\right) d S_{\text {North }}
\end{aligned}
$$

as the sum of $Q_{\text {advSouth }}$ and $Q_{\text {advNorth, the advections }}$ across the southern and northern interfaces denoted by $S_{\text {South }}$ and $S_{\text {North }}$. Similarly, the total heat advection to the whole domain is identified as the sum of advections across all bounding interfaces of the domain.

For our calculations, $h$ approximates the averaged mixed layer depth and is fixed as $100 \mathrm{~m}$, following Oliver et al. (2017). Notably, our results are insensitive to other mixed layer depth choices (e.g., $50 \mathrm{~m}$ ). The area $A$ is the SEAus region. We note that perfect heat budget closure is not expected here, since BRAN2016 is an ocean reanalysis product, which does not conserve energy due to the way that observational data were assimilated.

Via the heat budget, we examined the relative contribution of total advection to heat tendency anomalies during MHWs and summarized the proportion of MHWs dominated by advection. We further investigated advections in the zonal, meridional and vertical directions and demonstrate the connection between Tasman Sea MHWs and the intensified EAC Extension.

\section{d. East Australian Current Extension transport}

To link the local physical processes and the large-scale forcing mechanisms of the Tasman Sea MHWs, we are interested in the EAC Extension, especially its variability in the (upper-ocean) transport connected with both the meridional advection locally and the largescale wind-forced SSH responses (propagation) across the South Pacific. Here, the EAC Extension transport is defined as the southward transport in the upper $500 \mathrm{~m}$ between $150.1^{\circ}$ and $154.6^{\circ} \mathrm{E}$ along $37^{\circ} \mathrm{S}$ from monthly meridional velocities provided by BRAN2016. This choice of transport definition is guided by the vertical structure of long-term mean meridional velocities across $37^{\circ} \mathrm{S}$ (Fig. 3). According to Fig. 3a, the long-term mean meridional velocity between $150.1^{\circ}$ and $154.6^{\circ} \mathrm{E}$ near the western boundary is larger than velocities anywhere else. Within this longitude band, the EAC Extension flows southward and its northward recirculation to the east is also included as part of the boundary current system. The distribution of high standard deviations of the meridional velocity field indicates the strong variability in the upper $500 \mathrm{~m}$, characterizing the depth range of the upper EAC Extension (Fig. 3b). 


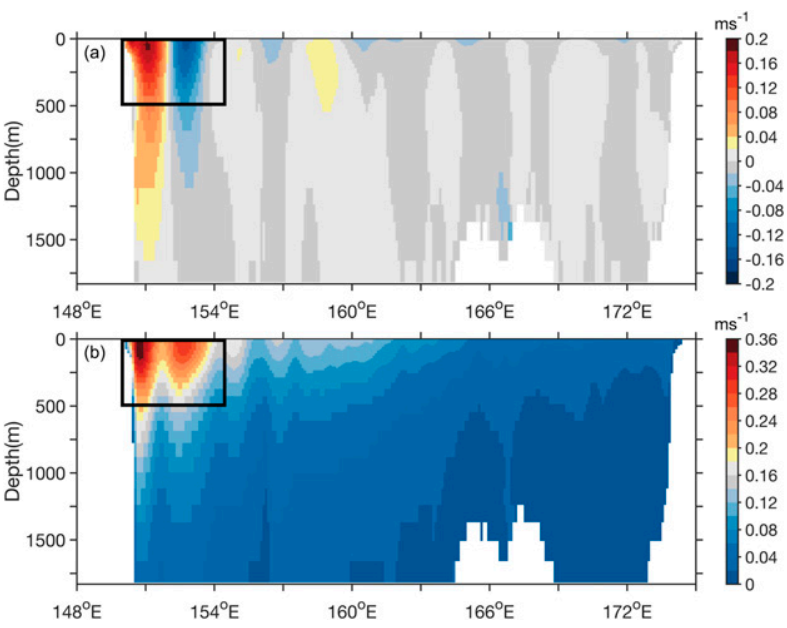

FIG. 3. Vertical structure of the meridional velocity along $37^{\circ} \mathrm{S}$ in the Tasman Sea. (a) Long-term mean meridional (positive southward) velocity. (b) Standard deviation of the meridional (positive southward) velocity. The rectangles highlight the area used for the calculation of the upper EAC Extension transport $\left(150.1^{\circ}-154.6^{\circ} \mathrm{E}\right.$, $0-500 \mathrm{~m})$.

\section{e. Lagged correlation analysis}

Variations in the EAC Extension transport are expected to be connected to the variability of the South Pacific wind field, with Rossby waves playing an important role in the dynamical processes. To identify the specific roles of Rossby waves, we focus on the relationship between EAC Extension transport anomalies and westward-propagating (incoming) SSH anomalies, which can be seen as surface signatures of Rossby wave propagation across the South Pacific (e.g., Chelton and Schlax 1996). We applied lagged correlation analysis between the detrended monthly EAC Extension transport and South Pacific SSH anomalies derived from BRAN2016 to examine their correlations at different lags. By arranging a series of obtained correlation maps in chronological order, we identified the potential relationship between EAC Extension variations and the basin-scale SSH variations-thus suggesting the importance of Rossby waves.

\section{f. Baroclinic and barotropic Rossby wave models}

To dynamically understand the contribution of Rossby waves and the relationship between Rossby waves and changes in the ocean-basin wind field, we applied two different Rossby wave models to evaluate SSH changes caused by baroclinic and barotropic responses to changes in the South Pacific wind stress curl.

For the baroclinic response, we adopted a 1.5-layer reduced-gravity long Rossby wave model (e.g., Qiu and Chen 2006). This type of model has been employed in previous studies to investigate SSH variations from the tropics to the midlatitudes (e.g., Sturges and Hong 1995; Holbrook and Bindoff 1999; Qiu 2002). Derived from the linear vorticity equation under the longwave approximation, the model equation can be written as

$$
\frac{\partial h_{\mathrm{bc}}}{\partial t}-c_{R} \frac{\partial h_{\mathrm{bc}}}{\partial x}=-\frac{g^{\prime} \operatorname{curl} \tau}{\rho g f}-\varepsilon h_{\mathrm{bc}},
$$

where $c_{R}\left(\mathrm{~m} \mathrm{~s}^{-1}\right)$ is the phase speed of the long baroclinic Rossby waves, $\tau\left(\mathrm{N} \mathrm{m}^{-2}\right)$ is the wind stress vector, $\rho\left(\mathrm{kg} \mathrm{m}^{-3}\right)$ is the reference density, $g^{\prime}\left(\mathrm{m} \mathrm{s}^{-2}\right)$ is the reduced gravity, $f\left(\mathrm{~s}^{-1}\right)$ is the Coriolis parameter, and $\varepsilon$ $\left(\mathrm{yr}^{-1}\right)$ is the Newtonian damping rate. Our interest is in $h_{\mathrm{bc}}(\mathrm{m})$, the SSH associated with baroclinic Rossby waves. To estimate $h_{\mathrm{bc}}$, Eq. (4) is integrated from the eastern boundary $\left(x=x_{E}\right)$ along the westward trajectories of the baroclinic Rossby wave to derive the following expression (e.g., Qiu and Chen 2006; Sasaki et al. 2008):

$$
h_{\mathrm{bc}}(x, y, t)=\underbrace{\frac{g^{\prime}}{\rho g f c_{R}} \int_{x_{E}}^{x} \operatorname{curl} \tau\left(x^{\prime}, y, t+\frac{x-x^{\prime}}{c_{R}}\right) \exp \left[\frac{\varepsilon\left(x-x^{\prime}\right)}{c_{R}}\right] d x^{\prime}}_{h_{i}(x, y, t)}+\underbrace{h\left(x_{E}, y, t+\frac{x-x_{E}}{c_{R}}\right) \exp \left[\frac{\varepsilon\left(x-x_{E}\right)}{c_{R}}\right]}_{h_{b}(x, y, t)},
$$

in which the term $h_{i}(x, y, t)$ is denoted as the contribution due to the interior wind forcing and the term $h_{b}(x, y, t)$ is denoted as the contribution of SSH along the eastern boundary with zonal coordinates $x$ and meridional coordinates $y$.

According to Qiu and Chen (2006), $\varepsilon=(3 \mathrm{yr})^{-1}$ is adopted for the damping rate. The value of $c_{R}$ is estimated as the product of the propagation speed derived in Chelton et al. (1998) and a latitude-dependent amplification factor $\alpha(y)=1.0+0.025\left(y-10^{\circ} \mathrm{S}\right)$.
For the barotropic response, the model is derived from the steady-state Sverdrup balance and expressed as (e.g., Bowen et al. 2017)

$$
h_{\mathrm{bt}}(x, y, t)=\frac{f^{2}}{\beta g D \rho} \int_{x_{E}}^{x} \operatorname{curl}\left[\frac{\tau(x, y, t)}{f}\right] d x,
$$

where $h_{\mathrm{bt}}(\mathrm{m})$ is the SSH induced by wind-forced barotropic Rossby waves, $\beta\left(\mathrm{m}^{-1} \mathrm{~s}^{-1}\right)$ is the Rossby parameter, and $D(\mathrm{~m})$ is the mean depth of the ocean basin. Following 

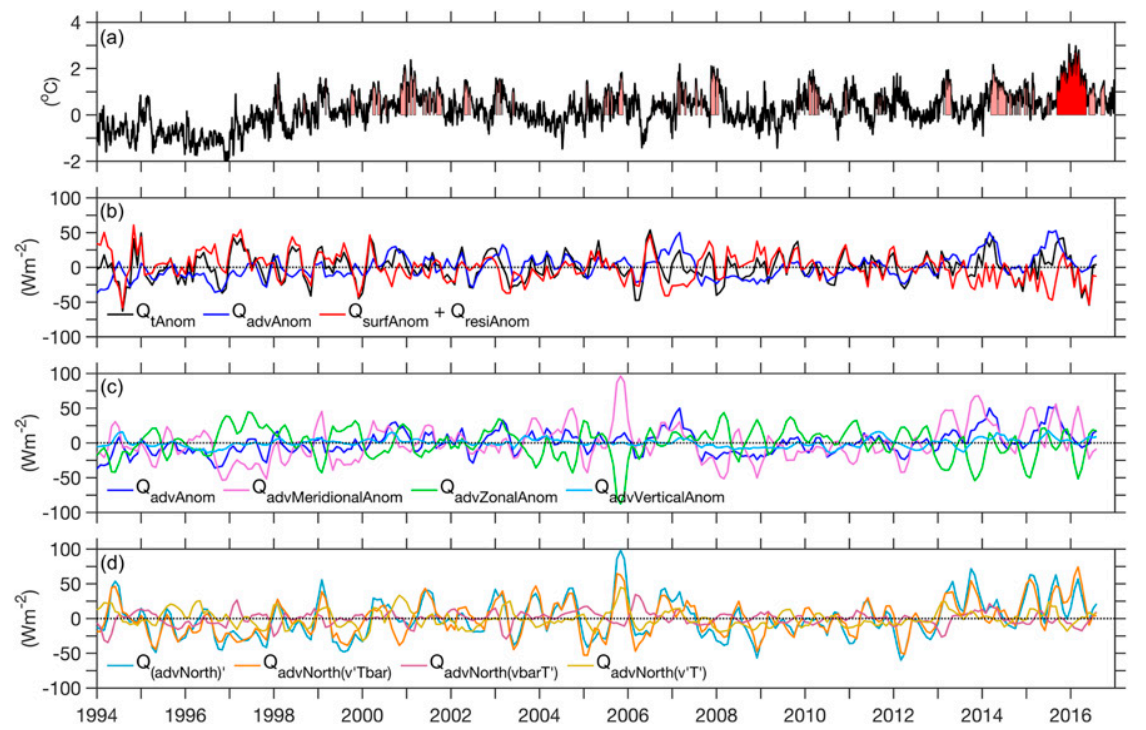

FIG. 4. Time series of (a) daily SST anomalies averaged over the SEAus region using NOAA OI SST with red-shaded area indicating the 2015/16 Tasman Sea MHW and the pink-shaded areas indicating historical MHWs detected using the quantitative definition of Hobday et al. (2016); (b) monthly anomalous heat tendency term $\left(Q_{t \text { Anom }}\right.$, black line) over the SEAus region and vertically down to 100 -m depth, along with contributions due to heat advection $\left(Q_{\text {advAnom }}\right.$, blue line) and all other factors including air-sea heat flux $\left(Q_{\text {surfanom }}+Q_{\text {resiAnom }}\right.$, red line); (c) advection contribution shown in (b) $\left(Q_{\text {advAnom }}\right.$, blue line $)$ and its meridional ( $Q_{\text {advMeridionalAnom }}$,

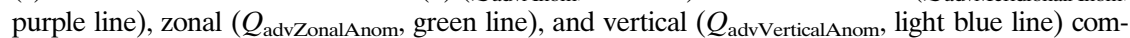
ponents; and (d) monthly anomalies of inward heat advection across the northern interface of the domain $\left(Q_{(\text {advNorth) }}\right.$, blue line) and its contribution due to the advection of mean seasonal temperature by anomalous velocity $\left(Q_{\text {advNorth }\left(v^{\prime} T \mathrm{bar}\right)}\right.$, orange line $)$, the advection of anomalous temperature by mean seasonal velocity $\left(Q_{\text {advNorth }(v \operatorname{bar} T)}\right)$, fuchsia line $)$ and the advection of anomalous temperature by anomalous velocity $\left(Q_{\text {advNorth }\left(v^{\prime} T^{\prime}\right)}\right.$, olive yellow line).

Bowen et al. (2017), $D$ is taken as $4000 \mathrm{~m}$ here. Considering the fast propagation speed of barotropic Rossby waves, Eq. (6) neglects the time-dependent term, which is indirectly accounted for by integration from the eastern boundary $\left(x=x_{E}\right)$ west along the barotropic Rossby wave characteristics.

In our study, we applied both the barotropic and baroclinic models "forced" by wind stresses to obtain the modeled SSH variations over the South Pacific. By comparing the model results with SSH and wind stress curl variations from BRAN2016, we investigated the connection between Rossby waves and changes in wind stress curl across the South Pacific, verifying the effects of remote wind forcing in the South Pacific on the EAC Extension variability and hence the occurrence of advection-dominated MHWs in the Tasman Sea.

\section{Results}

\section{a. Connection between Tasman Sea MHWs and EAC Extension}

After applying the MHW definition (Hobday et al. 2016) to 1994-2016 daily NOAA OI SST data in the
SEAus region, we identified a total of 71 MHWs from January 1994 to August 2016 (Fig. 4a; see Table A1 for details). The longest and most intense MHW in this 23yr record occurred from September 2015 to May 2016 (Fig. 4a, red shaded area). This 2015/16 MHW is identified to be due to the anomalously strong EAC Extension at that time (Oliver et al. 2017).

To examine the potential connection between other MHWs in the region and ocean advection, we performed a daily heat budget analysis over the SEAus region, using data from BRAN2016 in which SST anomalies are highly correlated with those derived from NOAA OI SST (not shown). By averaging daily values to monthly values, Fig. 4b shows the monthly volume-averaged heat tendency anomalies and its contributions from heat advection and all other factors (i.e., the sum of the air-sea heat flux, diffusion, and the artificial term due to data assimilation) since 1994. We smoothed the time series in Fig. 4b with a 3-month running-mean filter. Although the upperocean heat budget is not strictly closed, our main conclusions are still valid, since the sum of heat advection and air-sea heat flux terms in the budget is strongly correlated with the heat tendency anomalies $(r=0.64$ 
for monthly time series, $p<0.05$, based on the $t$ statistic), indicating that they are able to together explain most heat tendency anomalies within the domain.

Comparing visually Figs. $4 \mathrm{a}$ and $4 \mathrm{~b}$, we found that a proportion of MHWs off southeast Australia were primarily caused by ocean advection, while other MHWs were primarily due to other factors (e.g., air-sea heat flux). To quantify the specific proportion of MHWs that were due to anomalous advection, we calculated the exact contribution percentage of advection to each MHW by integrating the contribution of heat advection to the daily heat tendency anomalies during the event. Here, we identify MHWs when advection was estimated to contribute more than half of the heat tendency anomalies as advection-dominated MHWs. Our calculations identify that $51 \%$ (36 out of 71 ) of the MHWs within our domain that occurred in the period 1994-2016 were advection-dominated MHWs. The remainder $(49 \%$; 35 out of 71$)$ are deemed to be caused by surface heat flux or other processes (see Table A1 for details).
To further explore the connection between the identified advection-dominated MHWs and the EAC Extension intensifications, we examined the source direction of the anomalous advections for these MHWs - specifically from the zonal, meridional, and vertical directions. We found that meridional advection anomalies strongly and positively contribute to advection anomalies over our study domain, while zonal advection anomalies have a relatively weak negative contribution and vertical advection anomalies are negligible most of the time (Fig. 4c). This relatively large positive contribution from meridional advection anomalies corresponds primarily to variations in the southward EAC Extension, which dominates the anomalous heat advection off southeast Australia.

The decomposition of advection at the northern interface confirms the dominant contribution from the EAC Extension. By separating variables in time mean and anomalies, we decomposed the advection across the northern interface of the domain $\left(Q_{\text {advNorth }}\right)$ as (e.g., Lee et al. 2004)

$$
\begin{aligned}
Q_{\text {advNorth }} & =-\rho c_{p} \int_{S_{\text {North }}} v\left(T_{\text {North }}-\langle T\rangle\right) d S_{\text {North }}=-\rho c_{p} \int_{S_{\text {North }}} v \delta T d S_{\text {North }} \\
& =-\rho c_{p} \int_{S_{\text {North }}}\left(\bar{v}+v^{\prime}\right)\left(\overline{\delta T}+\delta T^{\prime}\right) d S_{\text {North }} \\
& =-\rho c_{p} \int_{S_{\text {North }}} \bar{v} \overline{\delta T} d S_{\text {North }}-\rho c_{p} \int_{S_{\text {North }}} v^{\prime} \overline{\delta T} d S_{\text {North }}-\rho c_{p} \int_{S_{\text {North }}} \bar{\delta} \delta T^{\prime} d S_{\text {North }}-\rho c_{p} \int_{S_{\text {North }}} v^{\prime} \delta T^{\prime} d S_{\text {North }},
\end{aligned}
$$

where overbars indicate climatological (seasonal) means and primes indicate nonclimatological anomalies. The four components shown in Eq. (7) represent the advection of climatological temperature by the climatological velocity, the advection of climatological temperature by the anomalous velocity, the advection of anomalous temperature by the climatological velocity, and the advection of anomalous temperature by the anomalous velocity (namely, the nonlinear advection term), respectively.

By comparing the magnitudes of the last three component terms in Eq. (7), we examined the relative contributions from anomalies in the velocity and temperature gradients to the heat advection across the northern interface. As shown in Fig. 4d, the anomalous heat advection across the northern interface, which represents the sum of the last three terms in Eq. (7), is primarily due to the advection of climatological temperature by the anomalous velocity, and weakly affected by the advection of anomalous temperature by the climatological velocity as well as the advection of anomalous temperature by the anomalous velocity. This indicates that the anomalous advection across the northern interface is dominated by the anomalies in velocity rather than temperature gradient. Therefore, the intensified EAC Extension, which manifests as anomalously strong southward velocities, primarily contributes to variations of heat advection across the northern interface and over the whole study domain, leading to the occurrences of the identified advection-dominated MHWs.

\section{b. Connection between EAC Extension transports and westward-propagating SSHs in the South Pacific}

We hypothesize that the anomalously strong EAC Extension, which was responsible for the 2015/16 Tasman Sea MHW and other significant advectiondominated MHWs off southeast Australia, is connected to enhanced wind stress curl in the South Pacific via westward-propagating SSH anomalies due to Rossby waves. We base our hypothesis on previous studies of the importance of Rossby waves on EAC transport variations in the region (e.g., Hill et al. 2010; Holbrook et al. 2011). To identify how EAC Extension 
transports are modulated by westward-propagating SSH anomalies, we applied lagged correlation analysis between the detrended monthly EAC Extension transport and South Pacific SSH anomalies. We smoothed the time series with a 7-month filter to highlight the influences of the large-scale processes and minimize the effects of eddies. We recognize that the definition of the EAC Extension transports and smoothing filter used are chosen somewhat arbitrarily. However, we examined different depths (e.g., $1000 \mathrm{~m}$ ) to represent the transports and different filters (e.g., 5-month filter) to smooth the data, and found that our conclusions were basically the same and not sensitive to these choices (not shown).

Figure 5 shows a series of correlation maps across the South Pacific, with different lags over a period of 70 months $(p<0.05$ for colored shading). Here we observe how the spatial structure of high correlations tracks the SSH anomalies that propagate to the western boundary, providing a large-scale picture of how the South Pacific SSH anomalies can influence the eastwest sea surface slope across the Tasman Sea and potentially modify the geostrophic transports in the EAC Extension. Beginning with the map with the longest lag, a cluster of SSH anomalies is seen in the central South Pacific at -70 months (Fig. 5 h). Following about 4 -yr westward propagation between $35^{\circ}$ and $40^{\circ} \mathrm{S}$, this cluster of SSH anomalies reached the east coast of New Zealand at -20 months (Figs. 5c-h). Interestingly, during this slow propagation, another cluster of SSH anomalies was also produced in the central South Pacific at -40 months (Fig. 5e). Compared to the other cluster of SSH anomalies, this cluster is seen to have propagated much faster, and traveled across the South Pacific between $35^{\circ}$ and $40^{\circ} \mathrm{S}$ in just over a few months. Owing to its much faster propagation, this cluster of SSH anomalies reached the east coast of New Zealand almost instantaneously at -40 months, earlier than the other cluster of SSH anomalies excited at -70 months (Fig. 5e). In the Tasman Sea, the SSH anomaly feature is located at the west coast of New Zealand from -30 months and observed to take 2-3 years propagating westward before reaching the EAC Extension at 0 month (Figs. 5a-d).

In Fig. 6, we constructed a time-longitude plot based on the large-scale perspective averaged between $35^{\circ}-40^{\circ} \mathrm{S}$ from the maps above. This was undertaken to further identify the propagating features and to understand the underlying mechanisms that modulate the EAC Extension transports associated with the westward-propagating SSH anomalies. Four groups of lines (labeled A, B, C, and D) have been drawn on Fig. 6 to examine the ranges and speeds of the different propagating features. Calculated from

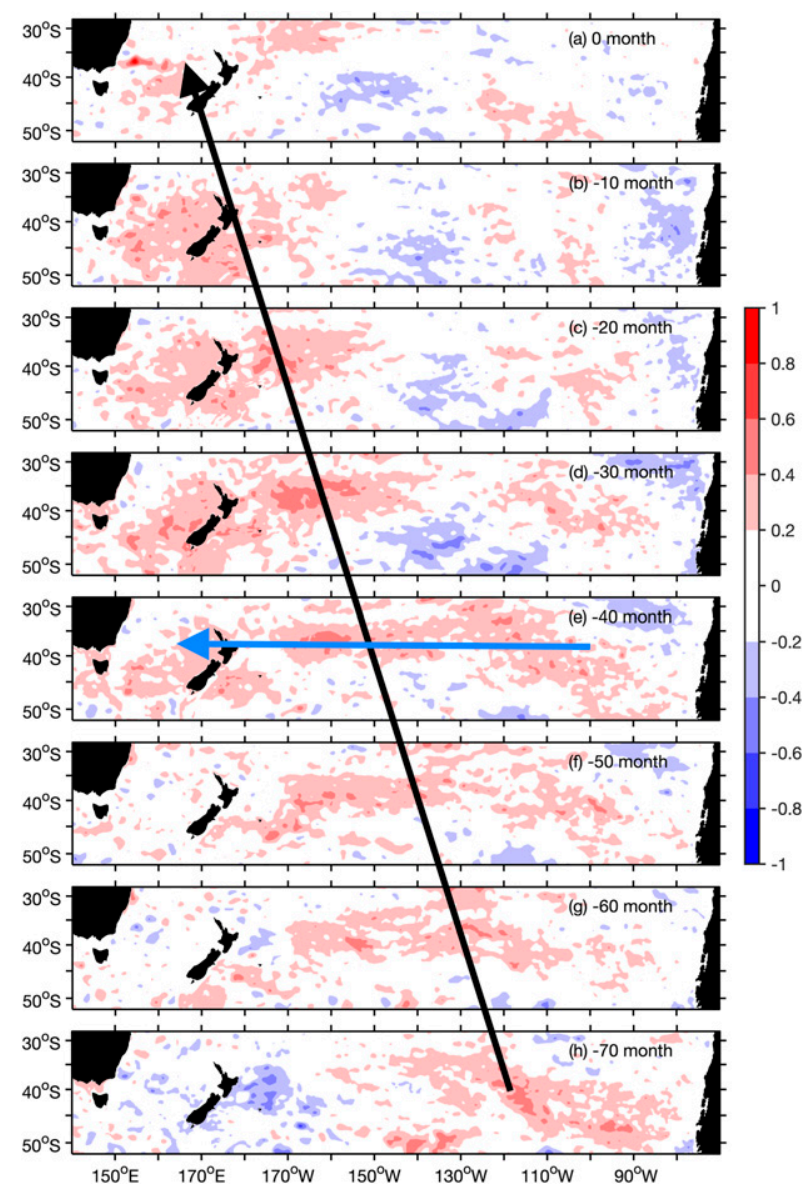

FIG. 5. Lagged correlation coefficients between the monthly EAC Extension transport anomalies and monthly SSH anomalies across the South Pacific. The monthly EAC Extension transports are calculated following details provided in section 2 and using BRAN2016. The SSH data are extracted from BRAN2016. Anomalies are relative to the 1994-2016 climatology (i.e., seasonal cycle removed). Black and blue arrows are used to indicate slowand fast-propagating features, which are likely to be characteristic of baroclinic and barotropic Rossby waves, respectively. Correlation coefficients with color shading are statistically significant with $95 \%$ confidence based on the $t$ statistic.

the lines labeled $\mathrm{A}$, the phase speed of the slow propagating feature in the South Pacific is approximately $3.10 \mathrm{~cm} \mathrm{~s}^{-1}$. This phase speed is well aligned with the phase speed for first baroclinic mode Rossby wave between $35^{\circ}$ and $40^{\circ} \mathrm{S}$ from altimeter observations (about $3 \mathrm{~cm} \mathrm{~s}^{-1}$ ) reported in the literature (e.g., Chelton and Schlax 1996). Thus, we justifiably suggest that these westward-propagating SSH anomalies are characteristic signatures of baroclinic Rossby waves. We also find that the signatures immediately propagate into the Tasman Sea after reaching the east coast of New Zealand. By estimating the slope of lines labeled $B$, we suggest that the new feature, which 


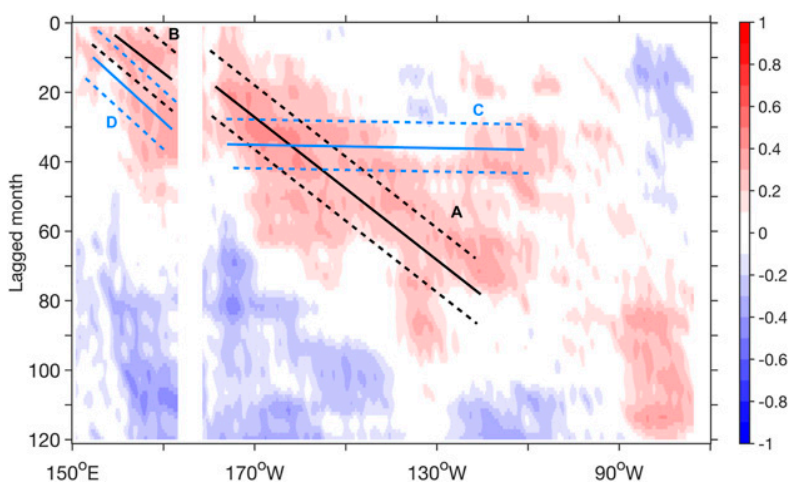

FIG. 6. A time-longitude plot of the lagged correlation coefficients between monthly EAC Extension transport anomalies and monthly SSH anomalies averaged between $35^{\circ}-40^{\circ} \mathrm{S}$ in the South Pacific. Solid lines indicate different propagating features and dashed lines further indicate the approximate ranges of these propagating features. The propagation speeds for features $\mathrm{A}$ and $\mathrm{B}$ are approximately 3.10 and $3.06 \mathrm{~cm} \mathrm{~s}^{-1}$ (black lines). The propagation speeds for features $\mathrm{C}$ and $\mathrm{D}$ are approximately $1.5 \mathrm{~m} \mathrm{~s}^{-1}$ and $2.95 \mathrm{~cm} \mathrm{~s}^{-1}$ (blue lines). Correlation coefficients with color shading are statistically significant with $95 \%$ confidence based on the $t$ statistic.

propagates at about $3.06 \mathrm{~cm} \mathrm{~s}^{-1}$, is also characteristic of baroclinic Rossby waves. Summarizing the features labeled $\mathrm{A}$ and $\mathrm{B}$, we conjecture a significant part of the underlying mechanism as follows. Wind-forced baroclinic Rossby waves take several years to propagate across the South Pacific before reaching the east coast of New Zealand. However, this signal does not stop there, but rather quickly travels to the west coast of New Zealand and excites new baroclinic Rossby waves that propagate westward across the Tasman Sea to the EAC Extension (Fig. 6, black lines). This is consistent with Liu et al. (1999), who explain that a coastal Kelvin wave propagates anticlockwise around New Zealand and excites baroclinic Rossby waves that propagate across the Tasman Sea, and suggests that remotely forced SSH anomalies in the central South Pacific take approximately 6-7 years to modulate the EAC Extension.

As for the fast-propagating feature in the South Pacific (labeled C in Fig. 6), we estimate the phase speed to be about $1.5 \mathrm{~m} \mathrm{~s}^{-1}$, which is in reasonable agreement with the speed of about $2.0 \mathrm{~m} \mathrm{~s}^{-1}$ for barotropic Rossby waves derived from Pedlosky (1996). Similar to the feature determined by lines labeled $\mathrm{B}$, the propagating feature with lines labeled $D$ is suggested as characteristic of baroclinic Rossby waves in the Tasman Sea. Within Fig. 6, we also observe a several-month discontinuity before the barotropic Rossby waves enter the Tasman Sea. This discontinuity can be explained by the conversion from barotropic to baroclinic Rossby waves at the ridges, according to Tanaka and Ikeda (2004).
We conjecture another component of the underlying mechanism by summarizing the features labeled $\mathrm{C}$ and $\mathrm{D}$, and the discontinuity between them. Despite taking only several months to travel across the South Pacific, wind-forced barotropic Rossby waves stall for roughly 6 months at the ridges, and there apparently convert to baroclinic Rossby waves before propagating across the Tasman Sea and influencing the EAC Extension (Fig. 6, blue lines). This is in accord with Liu et al. (1999) and Tanaka and Ikeda (2004) and suggests that remotely forced SSH anomalies in the central South Pacific take 3-4 years to influence the EAC Extension.

To further support the conjectured mechanism, we undertook a two-step additional analysis. In the first step, we compared the monthly EAC Extension transport anomalies (identified as advection-dominated MHWs) with the monthly SSH anomalies around New Zealand, which we selected as the average SSH anomalies within the trapezoidal region fixed by $34^{\circ} \mathrm{S}, 172^{\circ} \mathrm{E}$; $34^{\circ} \mathrm{S}, 179^{\circ} \mathrm{E} ; 47^{\circ} \mathrm{S}, 172^{\circ} \mathrm{E}$; and $47^{\circ} \mathrm{S}, 165^{\circ} \mathrm{E}$ (Fig. 1 , red box). A maximum correlation coefficient $(r=0.50, p<$ $0.05)$ is found when the comparison is between the EAC Extension transport anomaly and the 26month-lagged New Zealand box region-average SSH anomaly time series (Fig. 7a). The correlation coefficients with lags from 24 to 37 months are found to be similar (not shown). In Fig. 7a, the comparison not only illustrates that most of the Tasman Sea advection-dominated MHWs (including the 2015/16 MHW) appeared to occur in conjunction with EAC Extension intensifications, but also that these EAC Extension intensifications can be connected to the large positive SSH anomalies around New Zealand 26 months prior. This connection is in agreement with the mechanism of baroclinic Rossby wave propagation across the Tasman Sea.

We acknowledge that not all EAC Extension intensifications are well connected to the positive SSH anomalies around New Zealand exactly 26 months prior, as shown in Fig. 7a. We acknowledge that phase speeds of baroclinic Rossby waves can be influenced by other factors including bathymetry, western boundary shear, eddy instabilities, higher-order baroclinic modes, and thermodynamic processes (Perkins and Holbrook 2001). Thus, varying Rossby wave speeds might be expected as they traverse the complex bathymetry and region of the Tasman Sea. So, time scales on the order of 2-3 years, rather than exactly 26 months to traverse the Tasman Sea, are reasonable here. For the 2015/16 MHW, the EAC Extension intensification appears to be connected to the positive SSH anomaly around New Zealand during 2012-14. 


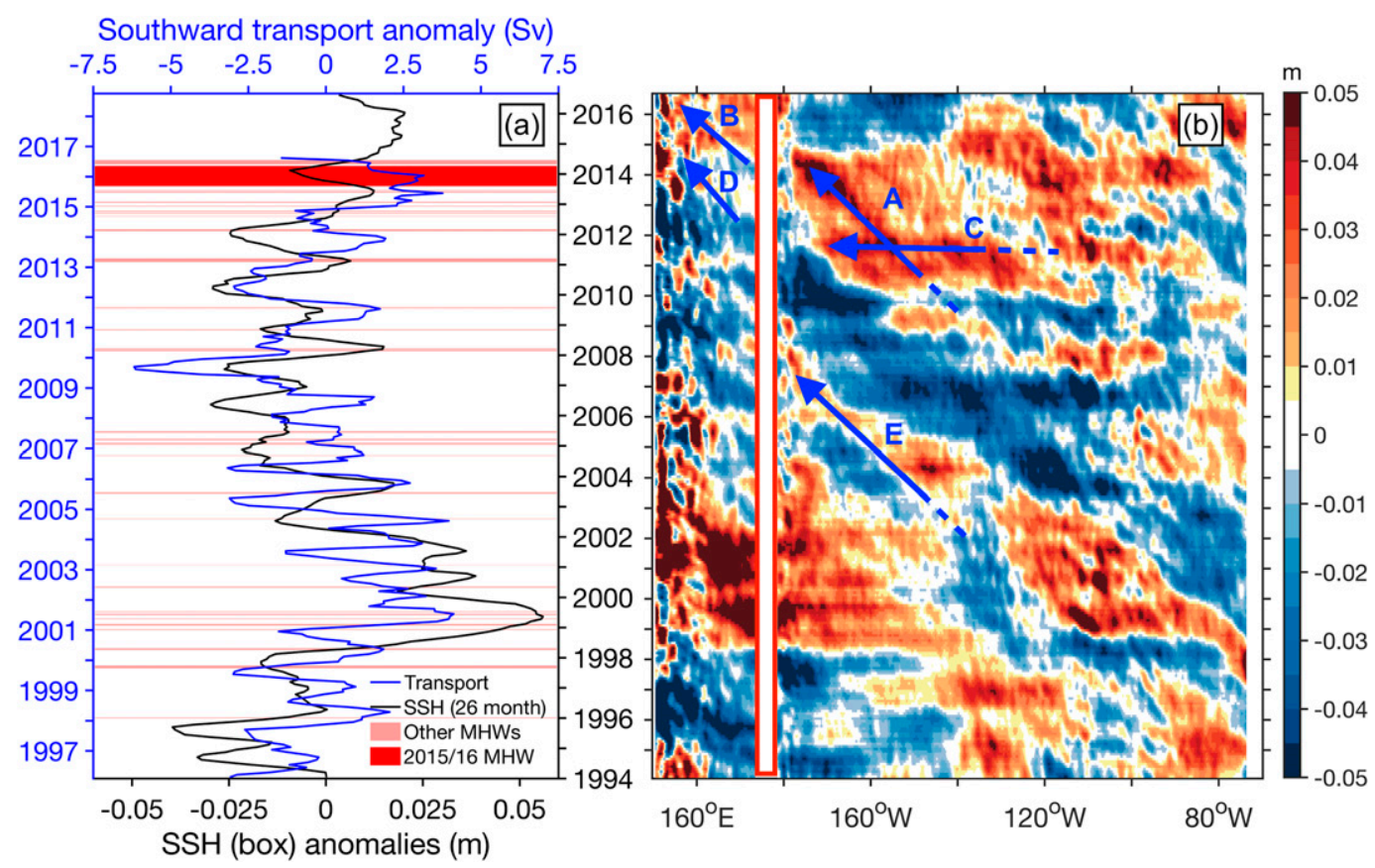

FIG. 7. (a) Time series of monthly EAC Extension transport anomalies across $37^{\circ} \mathrm{S}$ (blue line refers to left and upper axes), also marked with the estimated record of advection-dominated Tasman Sea MHWs off southeast Australia (red- and pink-shaded areas), plotted against average SSH anomalies around New Zealand (black line refers to right and bottom axes), with a 7-month filter and a 26-month lag of the SSH anomaly. (b) Time-longitude plot of monthly BRAN2016 SSH anomalies extending from the east coast of Australia to South America averaged between $35^{\circ}$ and $40^{\circ} \mathrm{S}$, also smoothed with a 7-month filter. Red box is used to indicate New Zealand. Blue arrows are used to indicate westward-propagating SSH anomalies.

In the second step, we analyzed the time-longitude plot of averaged $\mathrm{SSH}$ anomalies between $35^{\circ}$ and $40^{\circ} \mathrm{S}$ across the South Pacific (Fig. 7b). We found that the positive SSH anomalies around New Zealand (Fig. 7b, red box) mainly result from different westward-propagating features of SSH anomalies in the main ocean basin, which might reasonably be due to either strong baroclinic Rossby waves (e.g., positive SSH anomalies during 2007/ 08 ; Fig. 7b, arrow labeled E) or strong barotropic Rossby waves (e.g., positive SSH anomalies during 2012; Fig. 7b, arrow labeled C). In the case of the 2015/16 MHW, the corresponding positive SSH anomalies around New Zealand during 2012-14 might have been caused by substantial SSH anomalies from both baroclinic and barotropic Rossby waves (Fig. 7b, arrows labeled $A$ and $C)$.

In Fig. 7b, the westward-propagating features of SSH anomalies in the Tasman Sea also support the mechanism of baroclinic Rossby wave propagation discussed above. For the 2015/16 MHW, the corresponding baroclinic Rossby waves (Fig. 7b, arrows labeled B and D) are seen in the region since 2012. However, we acknowledge that these Rossby wave features are not as obvious as those in the main South Pacific basin and seem to be suppressed by small-scale signals in the Tasman Sea. This highlights the importance of other locally generated forcing factors in the Tasman Sea in also modulating regional $\mathrm{SSH}$ and the EAC Extension.

We acknowledge that there is some inconsistency between the occurrences of advection-dominated MHWs and the EAC Extension transport anomalies as well as SSH anomalies around New Zealand (Fig. 7). This inconsistency can be explained by the fact that the meridional advection anomalies are determined by both southward velocity anomalies associated with the EAC Extension and seasonal variations of temperature gradient [see Eq. (7)], together with the locally generated forcing factors arising from the complexity of the Tasman Sea topography and western boundary flow.

In this section, we have shown important connections between EAC Extension transport anomalies, SSH anomalies around New Zealand and the signatures of baroclinic and barotropic Rossby waves across the South Pacific. However, as lagged correlation and additional analyses are both empirical, we need further investigation to confirm the dynamical causality of these suggested oceanic teleconnection mechanisms. 

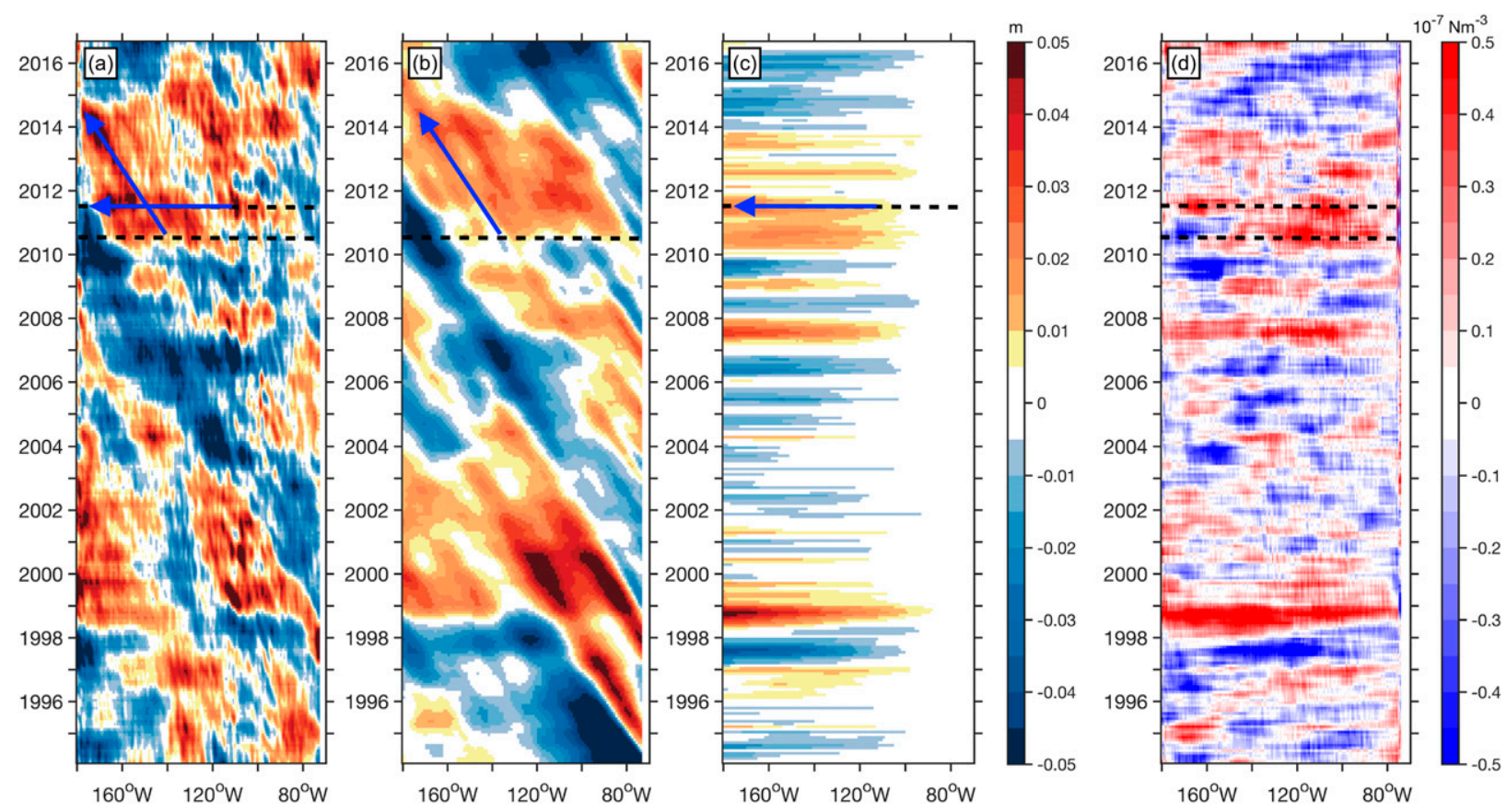

FIG. 8. Time-longitude plots of monthly SSH anomalies derived from (a) BRAN2016, (b) the baroclinic Rossby wave model, and (c) the barotropic Rossby wave model. (d) Time-longitude plot of monthly wind stress curl anomalies derived from BRAN2016. All timelongitude plots show results averaged between $35^{\circ}$ and $40^{\circ} \mathrm{S}$ from New Zealand to the west coast of South America for the period 1994 2016. Anomalies are calculated relative to the 1994-2016 climatology and smoothed with a 7-month filter. Dashed lines highlight an approximate time when the wind stress forcing of the baroclinic or barotropic Rossby waves associated with the 2015/16 Tasman Sea MHW appear to have been generated in the South Pacific. The solid blue arrows indicate the tracks of the two Rossby waves.

\section{c. Connection between westward-propagating SSHs and wind stress curl in the South Pacific}

We complete our understanding of the large-scale forcing of the 2015/16 MHW and other advectiondominated MHWs off southeast Australia by dynamically confirming the importance of Rossby waves and examining their generation driven by South Pacific wind forcing. To identify the Rossby wave generation with relatively specific time and location, we first attempted to identify the clear propagation pattern of each Rossby wave based on the SSH anomalies from BRAN2016. While propagating features for most Rossby waves within our timelongitude plot can be recognized, several apparent discontinuities along the propagating pathways obscure the propagating patterns of many Rossby waves (Fig. 8a). These results can be explained by the fact that Rossby wave characteristics can be modified by the superposition of local factors also acting along the propagation track, additional to the remote forcing by the winds that first generated them-this includes the effects of bathymetry and of atmosphere and ocean states (e.g., Vivier et al. 1999; Perkins and Holbrook 2001; Maharaj et al. 2005).

To better account for the effects of these local factors and to obtain a more complete understanding of the contribution from wind-forced Rossby waves, we used two Rossby wave models in which the wind stresses were used to force the baroclinic and barotropic Rossby waves separately across the South Pacific. For the baroclinic Rossby wave model [Eq. (4)], we initialized it using the monthly SSH along the eastern boundary of the South Pacific and applied monthly wind stresses across the South Pacific. The modeled SSH anomalies averaged between $35^{\circ}$ and $40^{\circ} \mathrm{S}$ in the South Pacific are shown as a time-longitude plot (Fig. 8b). For the barotropic Rossby wave model [Eq. (6)], the SSH anomalies averaged between $35^{\circ}$ and $40^{\circ} \mathrm{S}$ are characterized directly from the monthly South Pacific wind stresses (Fig. 8c). Compared to Fig. 8a, Figs. 8b and 8c capture well the relevant baroclinic and barotropic Rossby wave propagation patterns clearly and consistently, although there are some differences in the details that are likely due to the local factors not represented in either of these models. This dynamically confirms that the large-scale underlying mechanisms for EAC Extension transport anomalies are likely to be due to both baroclinic and barotropic Rossby waves in the South Pacific, as we suggested above. The correlation coefficient between SSH anomalies from BRAN2016 (Fig. 8a) and the sum of SSH anomalies generated by the two models is 0.72 

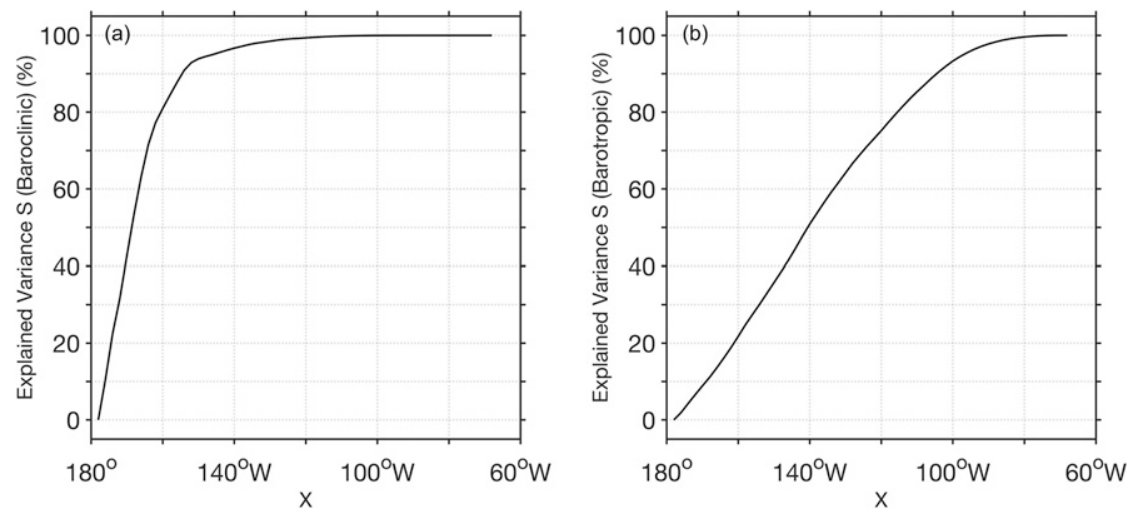

FIG. 9. Explained percentage of the variance of monthly simulated SSH anomalies averaged between $35^{\circ}$ and $40^{\circ} \mathrm{S}$ at the east coast of New Zealand from the (a) baroclinic and (b) barotropic Rossby wave models by the cumulative wind forcing from the east coast of New Zealand $\left(180^{\circ}\right)$ to a specific longitude east of $180^{\circ}$.

$(p<0.05$; Figs. $8 \mathrm{~b}$ and $8 \mathrm{c})$ at the east coast of New Zealand.

We acknowledge previous research has shown that simulated SSH anomalies from the baroclinic Rossby wave model may not reproduce the complexity and detail of westward-propagating signals seen in sophisticated models or observations (Perkins and Holbrook 2001; Fernandez et al. 2018). However, differences in explained variance of SSH anomalies are likely due to the many complex processes outlined above, including differences in simulation latitudes and wind forcing products.

After confirming the importance of Rossby waves in a dynamically based way, we have been able to closely estimate the change in wind stress curl that produced the corresponding Rossby waves by comparing the start of each propagating pathway with the wind stress curl anomalies around the same location in the longitudetime plot (Figs. 8b-d). For example, when we look at the 2015/16 Tasman Sea MHW, the corresponding baroclinic Rossby waves were produced between $130^{\circ}-$ $150^{\circ} \mathrm{W}$ in $2010 / 11$ and took about 5 years to reach the EAC Extension (Fig. 8, lower dashed lines and upward-sloping arrows). On the other hand, the corresponding barotropic Rossby waves took approximately 3-4 years to reach the EAC Extension region after they were first generated at about $100^{\circ}-120^{\circ} \mathrm{W}$ during 2011/12 (Fig. 8, upper dashed lines and horizontal arrows). Given the capability of tracking backward to the wind stress curl that produces the Rossby waves, we are able to verify the effects of remote wind forcing and their responses in the South Pacific on the EAC Extension variability and hence the occurrence of large-scale forced, advection-dominated MHWs in the Tasman Sea.
The Rossby wave models provide further opportunity to identify the source region of the wind stress curl anomalies that potentially influence the EAC Extension variability. As indicated in Fig. 7a, we found that the EAC Extension transport variability is connected to SSH changes around New Zealand, which reflects the cumulative effect of wind forcing along Rossby wave characteristics across the South Pacific. Importantly, the Rossby wave models can quantify the relative contributions of wind forcing over different parts of the South Pacific, by examining the cumulative variance of $\mathrm{SSH}$ anomalies at the east coast of New Zealand (i.e., western boundary of the main South Pacific basin) explained by wind stress curl west of longitude $X$ (Qiu and Chen 2010):

$$
S(X, y)=1-\frac{\left\{\left[H_{\mathrm{NZ}}^{\prime}\left(x_{E}, y, t\right)-H_{\mathrm{NZ}}^{\prime}(X, y, t)\right]^{2}\right\}}{\left\{H_{\mathrm{NZ}}^{\prime 2}\left(x_{E}, y, t\right)\right\}},
$$

where $\{\cdots\}$ denotes the summation over time and $H_{\mathrm{NZ}}^{\prime}(X, y, t)$ is defined as the SSH anomalies at the east coast of New Zealand $\left(x=x_{\mathrm{NZ}}\right)$ forced by the wind stress curl from the longitude $X$ to the east of New Zealand. By definition, $H_{\mathrm{NZ}}^{\prime}\left(x_{E}, y, t\right)$ represents the SSH changes forced by the wind stress curl across the whole South Pacific and $S\left(x_{E}, y\right)=1$ in Eq. (8).

For the baroclinic Rossby wave model, Fig. 9a reveals the result of $S(X)$, which suggests that the wind stress curl anomalies in the western portion of the South Pacific were responsible for most of the SSH changes (induced by baroclinic Rossby waves) at the east coast of New Zealand. Further, about $95 \%$ of the SSH variance can be explained by wind forcing west of $140^{\circ} \mathrm{W}$ (Fig. 9a). Dynamically, this can be understood considering the propagation speed of Rossby waves. Because 

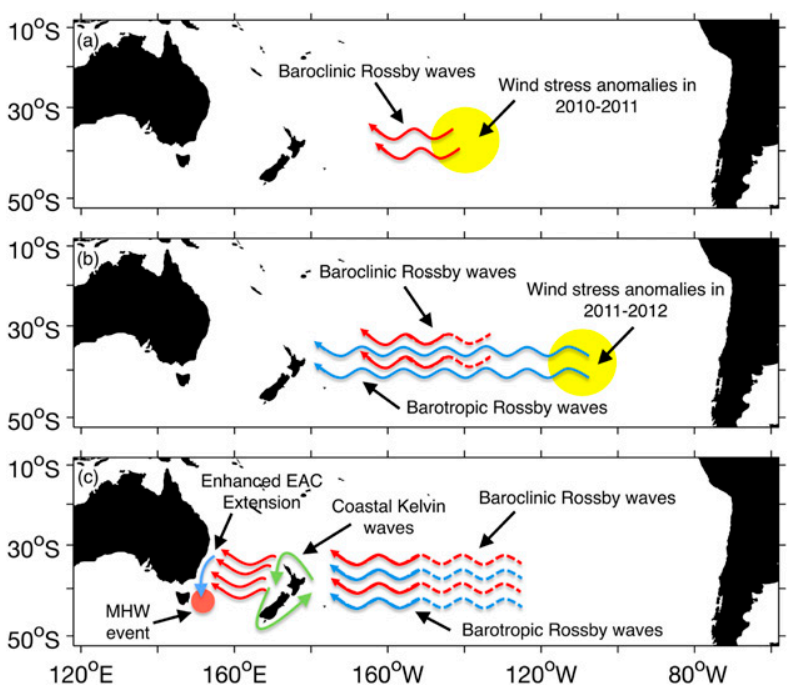

FIG. 10. Schematic of the large-scale forcing of the 2015/16 Tasman Sea MHW. (a) During 2010/11, enhanced wind stress curl anomalies generated slow baroclinic Rossby waves in the region $130^{\circ}-150^{\circ} \mathrm{W}$ of the South Pacific. (b) Around 2011/12, when the baroclinic Rossby waves were still propagating westward in the South Pacific, another period of enhanced wind stress curl anomalies that occurred in the region $100^{\circ}-120^{\circ} \mathrm{W}$ produced fast barotropic Rossby waves, which quickly crossed the ocean basin and reached the topographic ridges near the east coast of New Zealand. (c) Barotropic Rossby waves converted to baroclinic Rossby waves at these ridges, soon after which the baroclinic Rossby waves also reached New Zealand. New baroclinic Rossby waves were subsequently spawned at the west coast of New Zealand, which propagated westward through the Tasman Sea to apparently influence the EAC Extension.

it usually takes several years for baroclinic Rossby waves to travel across the South Pacific, such waves produced in the east basin of the South Pacific tend to be cancelled out on their way and therefore tend to contribute little to the SSH changes at the east coast of New Zealand. In contrast, baroclinic Rossby waves generated by winds in the western basin of the South Pacific can reach the New Zealand coast without destructive interference (cancellation) potentially exerting significant contribution to the SSH changes there.

For the barotropic Rossby wave model, Fig. $9 \mathrm{~b}$ reveals the result of $S(X)$, which indicates that the wind stress curl anomalies over the whole South Pacific play a relatively uniform role on the SSH changes at the east coast of New Zealand. This can also be dynamically understood with the propagation of barotropic Rossby waves. Due to their relatively fast propagation speed, barotropic Rossby waves can travel across the South Pacific in several weeks. Within such a short time, even the SSH signals from the eastern part of the
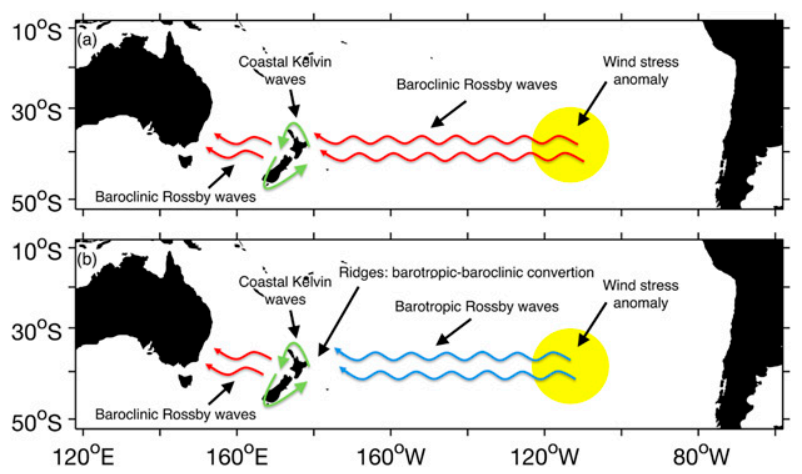

FIG. 11. Schematics of the (a) baroclinic Rossby wave mechanism and (b) barotropic-baroclinic Rossby wave mechanism.

South Pacific can quickly arrive at the east coast of New Zealand before being cancelled out.

\section{Discussion and conclusions}

In this study, we have investigated the large-scale drivers (forcing) of advection-dominated MHWs in the Tasman Sea, including the extreme 2015/16 Tasman Sea MHW. Our systematic investigation consisted of three parts. First, we demonstrated that $51 \%$ of the historical Tasman Sea MHWs identified since 1994 were caused by an intensified EAC Extension-based on a comparative analysis between detected MHWs and southward advective dominance determined from an upper-ocean heat budget analysis for the region. Second, we found potential links between modulations of the EAC Extension and westward-propagating SSH anomalies across the South Pacific-characteristic of baroclinic and barotropic Rossby waves via lagged correlation analysis. Third, by using baroclinic and barotropic Rossby wave models, we dynamically confirmed the links between the EAC Extension and Rossby waves in the South Pacific, and successfully tracked most Rossby waves back to their forcing associated with changes in the South Pacific wind stress curl. Collectively, our findings suggest that incoming Rossby waves, tracked as westward-propagating SSH anomalies across the South Pacific, can potentially enhance or reduce the likelihood of MHW occurrences in the Tasman Sea. This role of Rossby waves on Tasman Sea transports extends earlier research by Holbrook et al. (2011) and Hill et al. (2010), while the link to Tasman Sea MHW likelihoods provides more compelling evidence to support the hypothesis of these drivers in a recent global assessment of characteristic MHW mechanisms across 22 case study regions including the EAC Extension (Holbrook et al. 2019).

In 2010/11, 5-6 years prior to the extreme 2015/16 Tasman Sea MHW, the wind stress curl between $130^{\circ}$ 
TABLE A1. List of individual MHWs recorded for the SEAus region including the start and end dates of each event with their characteristics. The respective contributions of heat advection and other factors (i.e., the sum of the air-sea heat flux, horizontal and vertical diffusion, and the artificial term due to data assimilation) to the anomalous heat tendency during each MHW are also included. For the calculation of contributions, an 11-day window centered on each day of year is used for smoothing The last column also highlights the advection-dominated MHWs (Yes = an advection-dominated MHW; No = not an advection-dominated MHW).

\begin{tabular}{|c|c|c|c|c|c|c|c|c|}
\hline Start date & End date & $\begin{array}{l}\text { Duration } \\
\text { (days) }\end{array}$ & $\begin{array}{c}\text { Mean } \\
\text { intensity } \\
\left({ }^{\circ} \mathrm{C}\right)\end{array}$ & $\begin{array}{l}\text { Maximum } \\
\text { intensity } \\
\left({ }^{\circ} \mathrm{C}\right)\end{array}$ & $\begin{array}{c}\text { Cumulative } \\
\text { intensity } \\
\left({ }^{\circ} \mathrm{C}\right)\end{array}$ & $\begin{array}{c}\text { Contribution } \\
\text { due to } \\
\text { advection } \\
\left(\mathrm{W} \mathrm{m}^{-2}\right)\end{array}$ & $\begin{array}{l}\text { Contribution } \\
\text { due to } \\
\text { other factors } \\
\quad\left(\mathrm{W} \mathrm{m}^{-2}\right)\end{array}$ & $\begin{array}{l}\text { Advection } \\
\text { dominated }\end{array}$ \\
\hline 1 Feb 1998 & 8 Feb 1998 & 8 & 1.3 & 1.6 & 10.7 & 506.5 & 162.9 & Yes \\
\hline 4 Sep 1998 & 14 Sep 1998 & 11 & 0.7 & 0.9 & 8.1 & -90.1 & 251.0 & No \\
\hline 4 Jan 1999 & 8 Jan 1999 & 5 & 1.2 & 1.3 & 6.0 & 199.7 & 302.8 & No \\
\hline 2 Mar 1999 & 7 Mar 1999 & 6 & 1.3 & 1.4 & 7.8 & 74.7 & 652.7 & No \\
\hline 28 Sep 1999 & 30 Oct 1999 & 33 & 1.0 & 1.3 & 32.1 & 16.1 & -133.9 & Yes \\
\hline 27 Mar 2000 & 20 Apr 2000 & 25 & 1.2 & 1.4 & 29.6 & -292.3 & 1243.0 & No \\
\hline 7 May 2000 & 26 May 2000 & 20 & 1.1 & 1.5 & 22.3 & 120.4 & -745.0 & Yes \\
\hline 9 Jul 2000 & 17 Jul 2000 & 9 & 0.7 & 0.8 & 6.7 & 59.0 & 228.1 & No \\
\hline 12 Nov 2000 & 24 Dec 2000 & 43 & 1.4 & 2.1 & 61.2 & 1929.4 & 851.2 & Yes \\
\hline 4 Jan 2001 & 13 Jan 2001 & 10 & 1.3 & 1.4 & 12.8 & 362.1 & -1052.0 & Yes \\
\hline 28 Jan 2001 & 13 Feb 2001 & 17 & 1.6 & 2.2 & 26.4 & 170.2 & 184.4 & No \\
\hline 26 Feb 2001 & 16 Mar 2001 & 19 & 1.4 & 1.7 & 26.5 & -86.7 & -240.8 & Yes \\
\hline 14 May 2001 & 21 May 2001 & 8 & 1.0 & 1.2 & 8.1 & 86.4 & -26.2 & Yes \\
\hline 3 Jun 2001 & 14 Jun 2001 & 12 & 0.9 & 1.1 & 11.0 & 73.3 & 624.1 & No \\
\hline 3 Jul 2001 & 17 Jul 2001 & 15 & 1.0 & 1.2 & 14.6 & 552.3 & -447.0 & Yes \\
\hline 8 Aug 2001 & 16 Aug 2001 & 9 & 0.8 & 0.9 & 6.9 & 30.5 & 11.2 & Yes \\
\hline 4 Sep 2001 & 15 Oct 2001 & 42 & 1.0 & 1.5 & 41.7 & 236.8 & 939.8 & No \\
\hline 21 Apr 2002 & 22 May 2002 & 32 & 1.3 & 1.5 & 41.5 & 650.3 & 1101.4 & No \\
\hline 30 May 2002 & 12 Jun 2002 & 14 & 1.0 & 1.2 & 13.9 & -622.3 & -699.6 & Yes \\
\hline 11 Jan 2003 & 20 Jan 2003 & 10 & 1.3 & 1.4 & 12.6 & 88.5 & 593.5 & No \\
\hline 3 Feb 2003 & 13 Feb 2003 & 11 & 1.3 & 1.4 & 14.3 & 51.9 & 347.2 & No \\
\hline 25 Feb 2003 & 1 Mar 2003 & 5 & 1.2 & 1.3 & 5.9 & 240.6 & -592.8 & Yes \\
\hline 25 May 2003 & 6 Jun 2003 & 13 & 1.1 & 1.2 & 14.1 & -202.4 & 286.8 & No \\
\hline 6 Sep 2004 & 11 Sep 2004 & 6 & 0.7 & 0.8 & 4.4 & 69.7 & 1.6 & Yes \\
\hline 25 Jan 2005 & 1 Feb 2005 & 8 & 1.2 & 1.3 & 9.8 & -6.8 & 376.3 & No \\
\hline 19 Jun 2005 & 1 Jul 2005 & 13 & 0.9 & 1.2 & 11.9 & 200.4 & 1031.0 & No \\
\hline 10 Jul 2005 & 27 Jul 2005 & 18 & 1.0 & 1.3 & 18.2 & -125.1 & -348.2 & Yes \\
\hline 13 Aug 2005 & 26 Aug 2005 & 14 & 0.8 & 1.1 & 11.7 & -8.0 & 140.7 & No \\
\hline 16 Oct 2005 & 21 Nov 2005 & 37 & 1.3 & 1.8 & 47.1 & 117.8 & 1111.8 & No \\
\hline 11 Oct 2006 & 16 Oct 2006 & 6 & 0.9 & 1.0 & 5.3 & 180.4 & -17.6 & Yes \\
\hline 16 Feb 2007 & 25 Feb 2007 & 10 & 1.4 & 1.7 & 14.2 & 807.6 & -56.9 & Yes \\
\hline 1 Mar 2007 & 11 Mar 2007 & 11 & 1.4 & 2.0 & 15.3 & 864.1 & -1195.9 & Yes \\
\hline 12 Apr 2007 & 25 Apr 2005 & 14 & 1.2 & 1.4 & 16.8 & 56.6 & -350.5 & Yes \\
\hline 11 Jul 2007 & 26 Jul 2007 & 16 & 1.1 & 1.5 & 18.0 & 131.9 & -245.4 & Yes \\
\hline 24 Aug 2007 & 4 Sep 2007 & 12 & 0.8 & 1.0 & 9.4 & -316.2 & 314.9 & No \\
\hline 15 Nov 2007 & 22 Dec 2007 & 38 & 1.7 & 2.1 & 63.6 & -748.7 & 466.6 & No \\
\hline 28 Dec 2007 & 19 Jan 2008 & 23 & 1.5 & 1.9 & 34.3 & -569.5 & 253.1 & No \\
\hline 7 Nov 2009 & 12 Nov 2009 & 6 & 1.2 & 1.6 & 7.3 & 92.6 & 678.5 & No \\
\hline 27 Dec 2009 & 31 Dec 2009 & 5 & 1.3 & 1.3 & 6.3 & -40.9 & 158.5 & No \\
\hline 1 Feb 2010 & 22 Feb 2010 & 22 & 1.4 & 1.7 & 30.2 & -320.1 & 157.1 & No \\
\hline 3 Mar 2010 & 20 Mar 2010 & 18 & 1.4 & 1.8 & 25.3 & -510.6 & 1111.7 & No \\
\hline $24 \operatorname{Mar} 2010$ & 11 Apr 2010 & 19 & 1.1 & 1.3 & 20.6 & 3.9 & -190.1 & Yes \\
\hline 19 Apr 2010 & 27 Apr 2010 & 9 & 1.0 & 1.2 & 9.1 & 498.9 & 97.6 & Yes \\
\hline 28 Jul 2010 & 4 Aug 2010 & 8 & 0.8 & 0.9 & 6.3 & -98.6 & -12.8 & No \\
\hline 22 Nov 2010 & 27 Nov 2010 & 6 & 1.2 & 1.3 & 7.3 & -9.4 & 120.9 & No \\
\hline 1 Dec 2010 & 11 Dec 2010 & 11 & 1.3 & 1.6 & 14.6 & 48.8 & -197.6 & Yes \\
\hline 1 Aug 2011 & 6 Aug 2011 & 6 & 0.8 & 0.9 & 4.7 & -135.7 & 1179.7 & No \\
\hline 21 Aug 2011 & 26 Aug 2011 & 6 & 0.8 & 0.9 & 4.7 & 148.6 & -135.5 & Yes \\
\hline 1 Sep 2011 & 7 Sep 2011 & 7 & 0.8 & 0.9 & 5.3 & 210.8 & -685.0 & Yes \\
\hline 17 Sep 2011 & 23 Sep 2011 & 7 & 0.8 & 1.1 & 5.8 & -159.7 & 580.7 & No \\
\hline 18 Oct 2011 & 23 Oct 2011 & 6 & 1.0 & 1.2 & 6.2 & 100.8 & 308.6 & No \\
\hline 30 Dec 2011 & 3 Jan 2012 & 5 & 1.4 & 1.6 & 6.9 & -43.7 & 264.9 & No \\
\hline 16 Feb 2013 & 20 Feb 2013 & 5 & 1.2 & 1.4 & 6.2 & 144.9 & 240.0 & No \\
\hline 5 Mar 2013 & 18 Apr 2013 & 45 & 1.4 & 1.9 & 63.3 & 913.3 & -136.9 & Yes \\
\hline 13 Mar 2014 & 6 Apr 2014 & 55 & 1.5 & 2.2 & 81.4 & 3092.9 & -1156.9 & Yes \\
\hline 14 May 2014 & 17 Jul 2014 & 65 & 1.2 & 1.6 & 75.7 & 281.6 & 385.3 & No \\
\hline 21 Jul 2014 & 27 Jul 2014 & 7 & 0.8 & 0.9 & 5.7 & -45.5 & 195.0 & No \\
\hline
\end{tabular}


TABLE A1. (Continued)

\begin{tabular}{|c|c|c|c|c|c|c|c|c|}
\hline Start date & End date & $\begin{array}{c}\text { Duration } \\
\text { (days) }\end{array}$ & $\begin{array}{c}\text { Mean } \\
\text { intensity } \\
\left({ }^{\circ} \mathrm{C}\right)\end{array}$ & $\begin{array}{l}\text { Maximum } \\
\text { intensity } \\
\left({ }^{\circ} \mathrm{C}\right)\end{array}$ & $\begin{array}{c}\text { Cumulative } \\
\text { intensity } \\
\left({ }^{\circ} \mathrm{C}\right)\end{array}$ & $\begin{array}{c}\text { Contribution } \\
\text { due to } \\
\text { advection } \\
\left(\mathrm{W} \mathrm{m}^{-2}\right)\end{array}$ & $\begin{array}{l}\text { Contribution } \\
\text { due to } \\
\text { other factors } \\
\quad\left(\mathrm{W} \mathrm{m}^{-2}\right)\end{array}$ & $\begin{array}{l}\text { Advection } \\
\text { dominated }\end{array}$ \\
\hline 13 Aug 2014 & 29 Aug 2014 & 17 & 0.8 & 1.0 & 14.0 & -107.2 & 1099.5 & No \\
\hline 6 Sep 2014 & 11 Sep 2014 & 6 & 0.8 & 0.8 & 4.6 & 32.0 & -13.2 & Yes \\
\hline 26 Sep 2014 & 30 Sep 2014 & 5 & 0.8 & 0.9 & 3.9 & 37.9 & 93.9 & No \\
\hline 9 Oct 2014 & 15 Oct 2014 & 7 & 1.0 & 1.1 & 6.7 & 168.5 & -118.0 & Yes \\
\hline 23 Oct 2014 & 27 Oct 2014 & 5 & 0.9 & 1.0 & 4.5 & 12.7 & -159.3 & Yes \\
\hline 5 Nov 2014 & 14 Nov 2014 & 10 & 1.0 & 1.2 & 10.3 & -10.0 & -396.7 & Yes \\
\hline 14 Dec 2014 & 25 Dec 2014 & 12 & 1.3 & 1.5 & 15.1 & 189.3 & 460.4 & No \\
\hline 6 Jan 2015 & 13 Jan 2015 & 8 & 1.2 & 1.4 & 9.8 & -31.1 & -214.0 & Yes \\
\hline 20 Feb 2015 & 4 Mar 2015 & 13 & 1.1 & 1.6 & 15.3 & -40.8 & -628.5 & Yes \\
\hline 23 Jun 2015 & 4 Jul 2015 & 12 & 0.8 & 0.9 & 9.7 & 373.2 & 156.9 & Yes \\
\hline 9 Jul 2015 & 13 Jul 2015 & 5 & 0.8 & 3.8 & 3.8 & 144.9 & -42.8 & Yes \\
\hline $20 \mathrm{Jul} 2015$ & $25 \mathrm{Jul} 2015$ & 6 & 0.8 & 0.9 & 4.9 & 96.8 & -174.4 & Yes \\
\hline 9 Sep 2015 & 10 May 2016 & 245 & 1.8 & 3.0 & 434.4 & 2536.3 & 762.0 & Yes \\
\hline 30 May 2016 & 21 Jul 2016 & 53 & 1.0 & 1.3 & 54.0 & 405.4 & -693.8 & Yes \\
\hline
\end{tabular}

and $150^{\circ} \mathrm{W}$ in the interior South Pacific was enhanced, and initiated the westward propagation of both slow baroclinic Rossby waves and fast barotropic Rossby waves expressed as positive SSH anomalies in the midlatitudes (Fig. 10a). In 2011/12, while the baroclinic Rossby waves propagated across the South Pacific, another period of enhanced wind stress curl excited fast barotropic Rossby waves (and slow baroclinic Rossby waves). These anomalies continued throughout 2011/ 12 between $100^{\circ}$ and $120^{\circ} \mathrm{W}$ in the midlatitudes. The excited barotropic Rossby waves quickly traveled across the South Pacific and reached the topographic ridges near New Zealand within a few months (Fig. 10b). Previous research shows that barotropic Rossby waves can stall at the ridges for several months in order to convert to baroclinic Rossby waves, whereas in contrast baroclinic Rossby waves can immediately cross the ridges (Tanaka and Ikeda 2004; Hill et al. 2010). Thus, the SSH anomalies, expressed by these two types of waves, propagated around New Zealand to the west coast separated by only a few months. New baroclinic Rossby waves were then spawned and propagated westward from New Zealand's west coast toward Australia across the Tasman Sea, which resulted in an intensification of the EAC Extension and heat advection to play a critically important role in the 2015/16 Tasman Sea MHW 2-3 years after the Rossby waves left the west coast of New Zealand (Fig. 10c).

More generally, our results demonstrate similar large-scale forcing mechanisms for other advectiondominated MHWs off southeast Australia from 1994 to 2016. Here, we suggest two mechanisms (Fig. 11). Enhanced wind stress curl in the interior South Pacific can produce both slow baroclinic Rossby waves and fast barotropic Rossby waves. For the first mechanism, the slow baroclinic Rossby waves take several years to cross the South Pacific in the subtropics to midlatitudes. On reaching the New Zealand coast, the SSH anomalies rapidly propagate around New Zealand as a Kelvin wave and then excite new baroclinic Rossby waves that propagate westward from New Zealand's west coast across the Tasman Sea, and which modulate the EAC Extension leading to advection-type MHWs. We term and summarize this as the "baroclinic Rossby wave mechanism" for Tasman Sea MHWs (Fig. 11a). For the second mechanism, barotropic Rossby waves quickly propagate across the South Pacific and convert to baroclinic Rossby waves at the ridges near New Zealand and several months later a Kelvin wave that propagates around New Zealand. Again, baroclinic Rossby waves are generated and propagate from New Zealand's west coast, which modulate the EAC Extension transports resulting in advection-type Tasman Sea MHWs after a few years. We term and summarize this mechanism as the "barotropic-baroclinic Rossby wave mechanism" for Tasman Sea MHWs (Fig. 11b). Both mechanisms are consistent dynamical considerations of Liu et al. (1999) and Tanaka and Ikeda (2004). Here, however, we have further demonstrated that these mechanisms also apply to the potential development of advection-dominated Tasman Sea MHWs.

In the Tasman Sea, 51\% of MHWs since 1994 were advection-dominated. Importantly, our analysis suggests that the likelihood of advection-dominated Tasman Sea MHWs (i.e., dominated by modulated EAC Extension transports) may arise from deterministic processes like the westward propagation of wind-forced baroclinic or barotropic Rossby waves. Moreover, our findings suggest there may be potential predictability of large-scale 
advection-dominated MHW likelihoods off southeast Australia up to several years in advance, due to the deterministic contribution from baroclinic and barotropic Rossby waves in modulating the EAC Extension transports. This is consistent with and extends research by Behrens et al. (2019) demonstrating that meridional oceanic heat transports dominate Tasman Sea heat content variations and thus influence the likelihood of regional MHWs. We further suggest that monthly SSH changes around New Zealand may be a useful index of this potential predictability.

Our study has primarily focused on remote largescale forcing mechanisms of advection-dominated Tasman Sea MHWs via oceanic teleconnections, and thus smaller-scale factors such as mesoscale eddies and local winds have not been specifically investigated. We recognize and acknowledge that other dynamic factors on local to regional scales (e.g., Bull et al. 2017; Holbrook et al. 2019), including intrinsic (nondeterministic) variability such as eddy instabilities, also play a critical role in western boundary current regions, and specifically here in the Tasman Sea associated with the EAC Extension. The EAC Extension primarily comprises of a succession of mesoscale eddies which can trap and transport warm anomalies southward through the Tasman Sea and is associated with strong instabilities (Perkins and Holbrook 2001; Oliver et al. 2015; Bull et al. 2017). It would be beneficial to investigate the influence of these more chaotic mesoscale disturbances further in future research, together with any cascading contributions from the more large-scale deterministic dynamics on these local smaller-scale variations.

Acknowledgments. The authors thank Ming Feng for his helpful comments on an early draft. We appreciate and acknowledge the valuable comments provided by the three reviewers. We wish to acknowledge use of BRAN2016 ocean reanalysis product (http://dapds00. nci.org.au/thredds/catalog/gb6/BRAN/catalog.html) and thank the BRAN group for making their product publicly available. N. J. Holbrook acknowledges support from the Australian Research Council Centre of Excellence for Climate Extremes (CE170100023). N. J. Holbrook and E. A. Cougnon also acknowledge support from the NESP Earth Systems and Climate Change Hub. X. Zhang acknowledges support from the Centre for Southern Hemisphere Oceans Research Centre (CSHOR), a joint research centre between QNLM and CSIRO, and also support from the NESP Earth Systems and Climate Change Hub Project 2.10. E. C. J. Oliver acknowledges support from the National Sciences and Engineering Research Council of Canada
Discovery Grant RGPIN-2018-05255 and from the Marine Environmental Observation, Prediction and Response Network (MEOAR) project "Drivers, predictability and fisheries impacts of ocean temperature extremes."

\section{APPENDIX}

\section{Tasman Sea MHWs: Characteristics and Associated Local Processes}

Table A1 shows individual MHWs over the SEAus region detected following the Hobday et al. (2016) methodology, including the characteristics and local physical processes of each event. For the characteristics, the start and end dates, duration, mean and maximum intensity, and cumulative intensity of each event are listed. For the associated local physical processes, the respective contributions of heat advection and other factors to the anomalous heat tendency during each event are shown in the table. The last column of the table also highlights the advection-dominated MHWs, defined as those events mostly contributed by advection compared to other factors.

\section{REFERENCES}

Anderson, D. L., and A. E. Gill, 1975: Spin-up of a stratified ocean, with applications to upwelling. Deep-Sea Res. Oceanogr. Abstr. 22, 583-596, https://doi.org/10.1016/0011-7471(75)90046-7.

Andres, M., Y. O. Kwon, and J. Yang, 2011: Observations of the Kuroshio's barotropic and baroclinic responses to basin-wide wind forcing. J. Geophys. Res., 116, C04011, https://doi.org/ 10.1029/2010JC006863.

Babcock, R. C., and Coauthors, 2019: Severe continental-scale impacts of climate change are happening now: Extreme climate events impact marine habitat forming communities along $45 \%$ of Australia's coast. Front. Mar. Sci., 6, 411, https:// doi.org/10.3389/fmars.2019.00411.

Banzon, V., T. M. Smith, T. M. Chin, C. Liu, and W. Hankins, 2016: A long-term record of blended satellite and in situ sea-surface temperature for climate monitoring, modeling and environmental studies. Earth Syst. Sci. Data, 8, 165-176, https:// doi.org/10.5194/essd-8-165-2016.

Behrens, E., D. Fernandez, and P. Sutton, 2019: Meridional oceanic heat transport influences marine heatwaves in the Tasman Sea on interannual to decadal timescales. Front Mar. Sci., 6, 228, https://doi.org/10.3389/fmars.2019.00228.

Benthuysen, J., M. Feng, and L. Zhong, 2014: Spatial patterns of warming off western Australia during the 2011 Ningaloo Niño: Quantifying impacts of remote and local forcing. Cont. Shelf Res., 91, 232-246, https://doi.org/10.1016/ j.csr.2014.09.014.

Bowen, M., J. Markham, P. Sutton, X. Zhang, Q. Wu, N. T. Shears, and D. Fernandez, 2017: Interannual variability of sea surface temperature in the southwest Pacific and the role of ocean dynamics. J. Climate, 30, 7481-7492, https://doi.org/10.1175/ JCLI-D-16-0852.1. 
Bull, C. Y., A. E. Kiss, N. C. Jourdain, M. H. England, and E. van Sebille, 2017: Wind forced variability in eddy formation, eddy shedding, and the separation of the East Australian current. J. Geophys. Res. Oceans, 122, 9980-9998, https://doi.org/ 10.1002/2017JC013311.

—,- , E. van Sebille, N. C. Jourdain, and M. H. England, 2018: The role of the New Zealand plateau in the Tasman Sea circulation and separation of the East Australian Current. J. Geophys. Res. Oceans, 123, 1457-1470, https://doi.org/ 10.1002/2017JC013412.

Cavole, L. M., and Coauthors, 2016: Biological impacts of the 2013-2015 warm-water anomaly in the northeast Pacific: Winners, losers, and the future. Oceanography, 29, 273-285, https://doi.org/10.5670/oceanog.2016.32.

Ceballos, L. I., E. Di Lorenzo, C. D. Hoyos, N. Schneider, and B. Taguchi, 2009: North Pacific Gyre Oscillation synchronizes climate fluctuations in the eastern and western boundary systems. J. Climate, 22, 5163-5174, https://doi.org/10.1175/2009JCLI2848.1.

Chelton, D. B., and M. G. Schlax, 1996: Global observations of oceanic Rossby waves. Science, 272, 234-238, https://doi.org/ 10.1126/science.272.5259.234

_- R. A. Deszoeke, M. G. Schlax, K. El Naggar, and N. Siwertz, 1998: Geographical variability of the first baroclinic Rossby radius of deformation. J. Phys. Oceanogr., 28, 433-460, https://doi.org/10.1175/1520-0485(1998)028 $<0433$ :GVOTFB $>2.0 . \mathrm{CO} ; 2$.

Deser, C., M. A. Alexander, and M. S. Timlin, 1999: Evidence for a wind-driven intensification of the Kuroshio Current Extension from the 1970s to the 1980s. J. Climate, 12, 1697-1706, https:// doi.org/10.1175/1520-0442(1999)012<1697:EFAWDI>2.0.CO;2.

Fernandez, D., M. Bowen, and P. Sutton, 2018: Variability, coherence and forcing mechanisms in the New Zealand ocean boundary currents. Prog. Oceanogr., 165, 168-188, https:// doi.org/10.1016/j.pocean.2018.06.002.

Ganachaud, A., and Coauthors, 2014: The Southwest Pacific Ocean Circulation and Climate Experiment (SPICE). J. Geophys. Res. Oceans, 119, 7660-7686, https://doi.org/10.1002/2013JC009678.

Gramenz, E., 2016: Tasmanian salmon: Hope falling water temperatures will help local farmers. Australian Broadcasting Corporation, accessed 3 May 2016, http://www.abc.net.au/news/ 2016-04-08/ cooler-waters-signal-relief-for-tas-salmon-producers/7310944.

Hill, K., S. Rintoul, P. Oke, and K. Ridgway, 2010: Rapid response of the East Australian Current to remote wind forcing: The role of barotropic-baroclinic interactions. J. Mar. Res., 68 , 413-431, https://doi.org/10.1357/002224010794657218.

Hobday, A. J., and Coauthors, 2016: A hierarchical approach to defining marine heatwaves. Prog. Oceanogr., 141, 227-238, https://doi.org/10.1016/j.pocean.2015.12.014.

Holbrook, N. J., and N. L. Bindoff, 1999: Seasonal temperature variability in the upper southwest Pacific Ocean. J. Phys Oceanogr., 29, 366-381, https://doi.org/10.1175/1520-0485(1999) 029<0366:STVITU > 2.0.CO;2.

- I. D. Goodwin, S. McGregor, E. Molina, and S. B. Power, 2011: ENSO to multi-decadal time scale changes in East Australian Current transports and Fort Denison sea level: Oceanic Rossby waves as the connecting mechanism. Deep-Sea Res. II, 58, 547558, https://doi.org/10.1016/j.dsr2.2010.06.007.

_ - and Coauthors, 2019: A global assessment of marine heatwaves and their drivers. Nat. Commun., 10, 2624, https:// doi.org/10.1038/s41467-019-10206-z.

Hughes, T. P., and Coauthors, 2018: Spatial and temporal patterns of mass bleaching of corals in the Anthropocene. Science, 359, 80-83, https://doi.org/10.1126/science.aan8048.
Kim, S.-B., T. Lee, and I. Fukumori, 2007: Mechanisms controlling the interannual variation of mixed layer temperature averaged over the Niño-3 region. J. Climate, 20, 3822-3843, https:// doi.org/10.1175/JCLI4206.1.

Lee, T., I. Fukumori, and B. Tang, 2004: Temperature advection: Internal versus external processes. J. Phys. Oceanogr., 34, 1936-1944, https://doi.org/10.1175/1520-0485(2004)034<1936: TAIVEP $>2.0 . \mathrm{CO} ; 2$.

Liu, Z., L. Wu, and H. Hurlburt, 1999: Rossby wave-coastal Kelvin wave interaction in the extratropics. Part II: Formation of island circulation. J. Phys. Oceanogr., 29, 2405-2418, https://doi.org/10.1175/1520-0485(1999)029<2405:RWCKWI> 2.0.CO;2.

Maharaj, A. M., P. Cipollini, and N. J. Holbrook, 2005: Observed variability of the South Pacific westward sea level anomaly signal in the presence of bottom topography. Geophys. Res. Lett., 32, L04611, https://doi.org/10.1029/2004GL020966.

Oke, P. R., and Coauthors, 2013: Towards a dynamically balanced eddy-resolving ocean reanalysis: BRAN3. Ocean Modell., 67, 52-70, https://doi.org/10.1016/j.ocemod.2013.03.008.

Oliver, E. C., 2019: Mean warming not variability drives marine heatwave trends. Climate Dyn., 53, 1653-1659, https://doi.org/ 10.1007/s00382-019-04707-2.

——, T. J. O'Kane, and N. J. Holbrook, 2015: Projected changes to Tasman Sea eddies in a future climate. $J$. Geophys. Res. Oceans, 120, 7150-7165, https://doi.org/ 10.1002/2015JC010993.

, J. A. Benthuysen, N. L. Bindoff, A. J. Hobday, N. J. Holbrook, C. N. Mundy, and S. E. Perkins-Kirkpatrick, 2017: The unprecedented 2015/16 Tasman Sea marine heatwave. Nat. Commun., 8, 16101, https://doi.org/10.1038/ncomms16101. , and Coauthors, 2018: Longer and more frequent marine heatwaves over the past century. Nat. Commun., 9, 1324, https://doi.org/10.1038/s41467-018-03732-9.

Pedlosky, J., 1996: Ocean Circulation Theory. Springer, 453 pp.

Perkins, M. L., and N. J. Holbrook, 2001: Can Pacific Ocean thermocline depth anomalies be simulated by a simple linear vorticity model? J. Phys. Oceanogr., 31, 1786-1806, https://doi.org/ 10.1175/1520-0485(2001)031<1786:CPOTDA > 2.0.CO;2.

Qiu, B., 2002: Large-scale variability in the midlatitude subtropical and subpolar North Pacific Ocean: Observations and causes. J. Phys. Oceanogr., 32, 353-375, https://doi.org/10.1175/15200485(2002)032<0353:LSVITM $>2.0$. CO 2 .

— , and S. Chen, 2006: Decadal variability in the large-scale sea surface height field of the South Pacific Ocean: Observations and causes. J. Phys. Oceanogr., 36, 1751-1762, https://doi.org/ 10.1175/JPO2943.1.

, and - 2010: Interannual-to-decadal variability in the bifurcation of the North Equatorial Current off the Philippines. J. Phys. Oceanogr., 40, 2525-2538, https://doi.org/10.1175/ 2010JPO4462.1.

— N. N. Schneider, and S. Chen, 2007: Coupled decadal variability in the North Pacific: An observationally constrained idealized model. J. Climate, 20, 3602-3620, https://doi.org/10.1175/JCLI4190.1.

Reynolds, R. W., T. M. Smith, C. Liu, D. B. Chelton, K. S. Casey, and M. G. Schlax, 2007: Daily high-resolution-blended analyses for sea surface temperature. J. Climate, 20, 5473-5496, https://doi.org/10.1175/2007JCLI1824.1.

Sasaki, Y. N., S. Minobe, N. Schneider, T. Kagimoto, M. Nonaka, and H. Sasaki, 2008: Decadal sea level variability in the South Pacific in a global eddy-resolving ocean model hindcast. J. Phys. Oceanogr., 38, 1731-1747, https://doi.org/10.1175/ 2007JPO3915.1. 
Smale, D. A., and Coauthors, 2019: Marine heatwaves threaten global biodiversity and the provision of ecosystem services. Nat. Climate Change, 9, 306-312, https://doi.org/10.1038/s41558-019-0412-1.

Stommel, H., 1948: The westward intensification of wind-driven ocean currents. Eos, Trans. Amer. Geophys. Union, 29, 202 206, https://doi.org/10.1029/TR029i002p00202.

Sturges, W., and B. Hong, 1995: Wind forcing of the Atlantic thermocline along $32^{\circ} \mathrm{N}$ at low frequencies. J. Phys. Oceanogr., 25, 1706-1715, https://doi.org/10.1175/1520-0485(1995)025<1706: WFOTAT $>2.0$.CO;2.

Sverdrup, H. U., 1947: Wind-driven currents in a baroclinic ocean; with application to the equatorial currents of the eastern Pacific. Proc. Natl. Acad. Sci. USA, 33, 318-326, https:// doi.org/10.1073/pnas.33.11.318.

Tanaka, K., and M. Ikeda, 2004: Propagation of Rossby waves over ridges excited by interannual wind forcing in a western North
Pacific model. J. Oceanogr., 60, 329-340, https://doi.org/ 10.1023/B:JOCE.0000038339.21509.83.

Vivier, F., K. A. Kelly, and L. Thompson, 1999: Contributions of wind forcing, waves, and surface heating to sea surface height observations in the Pacific Ocean. J. Geophys. Res., 104, 20 767-20 788, https://doi.org/10.1029/1999JC900096.

Zhang, X., and M. J. McPhaden, 2010: Surface layer heat balance in the eastern equatorial Pacific Ocean on interannual time scales: Influence of local versus remote wind forcing. J. Climate, 23, 4375-4394, https://doi.org/10.1175/ 2010JCLI3469.1.

—_, B. Cornuelle, and D. Roemmich, 2012: Sensitivity of western boundary transport at the mean North Equatorial Current bifurcation latitude to wind forcing. J. Phys. Oceanogr., 42, 2056-2072, https://doi.org/10.1175/JPO-D11-0229.1. 